\title{
The Use of Water Cooling during the Continuous Casting of Steel and Aluminum Alloys
}

\author{
J. SENGUPTA, B.G. THOMAS, and M.A. WELLS
}

In both continuous casting of steel slabs and direct chill (DC) casting of aluminum alloy ingots, water is used to cool the mold in the initial stages of solidification, and then below the mold, where it is in direct contact with the newly solidified surface of the metal. Water cooling affects the product quality by (1) controlling the heat removal rate that creates and cools the solid shell and (2) generating thermal stresses and strains inside the solidified metal. This work reviews the current stateof-the-art in water cooling for both processes, and draws insights by comparing and contrasting the different practices used in each process. The heat extraction coefficient during secondary cooling depends greatly on the surface temperature of the ingot, as represented by boiling water-cooling curves. Thus, the heat extraction rate varies dramatically with time, as the slab/ingot surface temperature changes. Sudden fluctuations in the temperature gradients within the solidifying metal cause thermal stresses, which often lead to cracks, especially near the solidification front, where even small tensile stresses can form hot tears. Hence, a tight control of spray cooling for steel, and practices such as $\mathrm{CO}_{2}$ injection/pulse water cooling for aluminum, are now used to avoid sudden changes in the strand surface temperature. The goal in each process is to match the rate of heat removal at the surface with the internal supply of latent and sensible heat, in order to lower the metal surface temperature monotonically, until cooling is complete.

\section{INTRODUCTION}

CONTINUOUS casting processes for both steel and aluminum alloys were developed several decades ago to produce shapes for subsequent semifabrication processes such as extrusion or rolling. As-cast product shapes include billets (square cross section with thickness less than $\sim 150$ to $175 \mathrm{~mm}$ for steel), thick slabs/ingots (wide rectangular cross section with thickness between $\sim 50$ and $300 \mathrm{~mm}$ for steel, and up to $\sim 500$ to $750 \mathrm{~mm}$ for aluminum alloys), thin slabs (thickness between $\sim 50$ and $75 \mathrm{~mm}$ for steel), strips (thickness between $\sim 1$ and $12 \mathrm{~mm}$ for both steel and aluminum alloys $)$, and rounds/extrusion billets $(\sim 100-$ to $\sim 500-\mathrm{mm}$ diameter for both steel and aluminum alloys). In recent decades, a dramatic growth of this primary metal processing technology has been realized in both steel and aluminum industries, owing to a substantial increase in yield, energy savings, and productivity over static casting. However, the technological advancement has taken distinctly different routes for these two metal industries. Over the years, the casting procedures for steel and aluminum alloy products have developed distinctive features in terms of casting practices, machinery, and process and quality control methodologies.

The productivity of both processes is controlled by the casting speed, so higher speeds are always sought. However, the casting speed cannot be increased arbitrarily for several reasons. ${ }^{[1]}$ First, the resulting increase in depth of the liquid pool and surface temperature of the strand prolongs the solidifica-

J. SENGUPTA, NSERC (Canada) Postdoctoral Fellow, and B.G. THOMAS, W. Grafton \& L.B. Wilkins Professor, are with the Department of Mechanical and Industrial Engineering, University of Illinois, Urbana, IL 61801. Contact e-mail: bgthomas@uiuc.edu M.A. WELLS, Assistant Professor, is with the Department of Materials Engineering, University of British Columbia, Vancouver, BC, Canada V6T 1 Z4.

Manuscript submitted May 10, 2004. tion process and increases the cooling requirements. In extreme cases, the structurally weak solid shell may rupture, leading to a "breakout" of liquid metal below the mold, or to excessive bulging if containment is exceeded for larger sections. Second, higher casting speeds often lead to cracks, caused by the higher thermal stresses. The practical range of operating speeds depends on alloy composition and product geometry. For steel slabs, the casting speed increases with decreasing thickness from $0.01 \mathrm{~ms}^{-1}$ (for $300-\mathrm{mm}$ blooms) to over $0.08 \mathrm{~ms}^{-1}$ (for 50-mm thin slabs). Owing to cracking difficulties during startup, aluminum alloy ingots and billets are cast at much lower speeds, increasing from $\sim 0.00075$ to $0.001 \mathrm{~ms}^{-1[2]}$ to steady speeds ranging from 0.001 to $0.003 \mathrm{~ms}^{-1[3]}$.

The continuous casting machinery is comprised of the mold and secondary water-cooling systems. These are designed to extract superheat from the incoming liquid metal $(\sim 5 \mathrm{pct}$ of the total heat content in the metal), latent heat of fusion at the solidification front $(\sim 20$ pct of total heat content), and heat of phase transformation and sensible heat $(\sim 75$ pct of the total heat content) from the solidified metal. However, the cooling system features for casting steel and aluminum alloys are very different, as schematically illustrated by Figures $1(\mathrm{a})^{[4]}$ (for steel) and (b) ${ }^{[5,6]}$ (for aluminum alloys).

In the conventional continuous (or strand) casting of steel, shown in Figure 1(a), liquid steel flows from the bottom of a ladle into a small intermediate vessel known as the tundish. It leaves the tundish bottom through a submerged nozzle, according to the position of a stopper-rod or slide-gate flow control system. The liquid flow is directed into the mold (usually $\sim 700$ to $1200 \mathrm{~mm}$ in length), and freezes a thin shell against the water-cooled copper walls. At steady state, the solid shell exiting the mold forms a stable strand, which has adequate mechanical strength to support the liquid metal core (typically 5 to $30 \mathrm{~m}$ in depth, depending on the casting speed and thickness). Motor-driven drive rolls located far below the mold continuously withdraw the strand downward. 


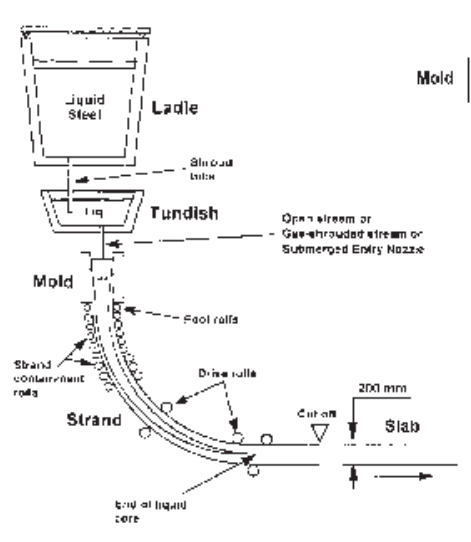

(a)

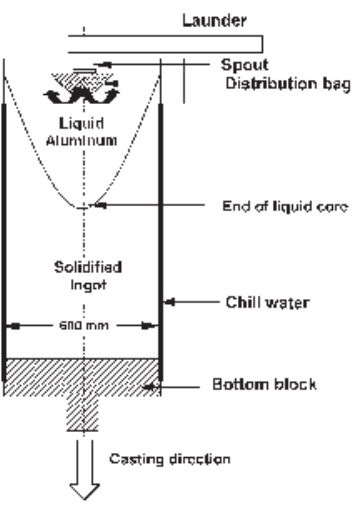

(b)
Fig. 1-Schematic of (a) the continuous casting process for steel slabs and billets $^{[4]}$ and $(b)$ the DC casting process for aluminum sheet ingots ${ }^{[5,6]}$.

Many closely spaced support rolls prevent the outward bulging of the shell due to the ferrostatic pressure arising from the liquid steel core. Water sprays emerge from highpressure nozzles, which are interspaced between the support rolls and cool the strand during the solidification process. Other strategically placed rolls bend the shell to follow a curved path and then straighten it flat prior to torch cutoff into individual slabs. This allows fully continuous operation. Start up of this process is a relatively rare occurrence, and is achieved by inserting a "dummy" bar to plug the mold bottom. Thus, the first steel cast in a sequence can be routinely downgraded or scrapped for defects without incurring a significant yield loss.

The direct chill (DC) casting process for aluminum alloys is shown schematically in Figure 1(b). In contrast to the continuous casting process for steel, DC casting is only semicontinuous; as the strand is withdrawn vertically for a short length $(\sim 10 \mathrm{~m})$ until the process must be stopped and restarted when the cast ingot reaches the bottom of the casting pit. Thus, considerable attention must focus on the initial start-up stage, when defects are most likely to be initiated. To start the process, a bottom block is partially inserted into an open rectangular mold (usually $\sim 100$ to $150 \mathrm{~mm}$ in length). Superheated liquid aluminum flows through a launder, down the nozzle spout, through a distribution bag, and into the mold, at a predetermined, time-varying filling rate. Once the molten metal fills the bottom block to a prescribed height, the bottom block and cast ingot are lowered into a casting pit. The aluminum ingot is subjected to cooling by the transfer of heat to the water-cooled aluminum mold over a very short length ( $\sim 70$ to $90 \mathrm{~mm}$ ), and to cooling through the contact of chill water with the solid shell after it emerges from the mold cavity. This water emerges from a series of holes, which surround the mold at its base. The defining character of the DC casting process is the extraction of heat due to this direct impingement of water on the ingot surface; typically, more than 80 pct of the total heat is removed by this method under steady-state conditions. ${ }^{[7]}$ The thermal field in this semicontinuous process can be considered to develop in two distinct stages. During the start up, or stage I, the liquid pool profile and thermal field continuously evolve with time. Then, during the steady state, or stage II, the liquid pool profile remains essentially constant or "fully developed" relative to the mold (typically, $\sim 200$ to $500 \mathrm{~mm}$ in depth depending on the ingot size and alloy composition ${ }^{[3,8]}$ ). Steady-state operation is usually achieved within a cast length of $\sim 0.5$ to $1 \mathrm{~m}$. Finally at the end of casting, the bottom block stops and the ingot is removed from the casting pit to cool.

Some of the contrasting features between the continuous casting of steel and DC casting of aluminum alloys can be attributed to the differences between the thermophysical properties of the two metals. Referring to Table $\mathrm{I},{ }^{[9,10,11]}$ these can be summarized as follows.

(1) The melting temperature of aluminum alloys is significantly lower than steel. As a consequence, continuous casting machines must remove more heat per unit mass of steel and operate in a higher temperature environment than aluminum alloys.

(2) The thermal conductivity of aluminum alloys is an order of magnitude higher than that of steel. Combined with the slower casting speed $(\sim 10$ times slower than steel continuous casting), this causes faster internal heat extraction, resulting in the relatively short liquid pool in DC casting of aluminum alloys mentioned earlier. To avoid cracking the solid strand, DC-cast ingots must be cast vertically without bending. This limits the cast length before it must be removed from the casting pit and production restarted for a new ingot. In contrast, the liquid metal pool during continuous casting of steel extends well below the mold. This results in a strand with a liquid-filled shell structure, which can be easily bent and straightened to generate a continuous supply of solidified semifinished product.

(3) The thermal diffusivity of liquid aluminum is about 6 times higher than that of liquid steel. This means that liquid aluminum tends to lose its superheat faster than liquid steel, for a given fluid flow pattern. Temperature profiles in the solid aluminum therefore respond faster to changes in surface heat removal.

(4) The solidification shrinkage experienced by aluminum alloys is almost twice that of steel. Therefore, higher thermal stresses can be generated within the solidification "mushy" zone by aluminum alloys, making hot tear cracks more likely, especially in alloys with long freezing ranges.

(5) The volumetric latent heat of aluminum is substantially less, making initial solidification at the meniscus much faster than in steel.

(6) The thermal contraction coefficient of solid aluminum is higher than in steel. During initial solidification, the extra contraction of the solid shell causes deeper surface depressions, resulting in a marked reduction in mold heat flow and surface quality problems. Also, the larger thermal contraction during DC casting leads to greater macrodeformation of aluminum ingots. One example is the characteristic deformation of the ingot base, called "butt curl," ${ }^{[5,12]}$ which develops during startup, especially when cooling water reaches the ingot surface within the base region. ${ }^{[13]}$ Under steady-state conditions, the solidifying ingot contracts, especially towards the face centers. To prevent this effect, called ingot rolling face "pull-in," most high-aspect-ratio molds are designed with convex shape. ${ }^{[14]}$

This article was undertaken to compare and contrast the heat-transfer phenomena in continuous casting of steel and 
Table I. Thermophysical Properties of Steel and Aluminum ${ }^{[9,10,11]}$

\begin{tabular}{|c|c|c|c|c|}
\hline Thermophysical Properties & Liquid Steel & Liquid Aluminum & Solid Steel & Solid Aluminum \\
\hline Liquidus temperature $\left({ }^{\circ} \mathrm{C}\right)$ & 1525 & 650 & - & - \\
\hline Density $\left(\mathrm{kg} \mathrm{m}^{-3}\right)$ & 7020 & 2400 & 8000 & 2600 \\
\hline Specific heat $\left(\mathrm{J} / \mathrm{kg}^{-1} \mathrm{~K}^{-1}\right)$ & 680 & 1300 & 690 & 900 \\
\hline Thermal conductivity $\left(\mathrm{W} \mathrm{m}{ }^{-1} \mathrm{~K}^{-1}\right)$ & 26 & 90 & 29 & 190 \\
\hline Thermal diffusivity $\left(\mathrm{m}^{2} \mathrm{~s}^{-1}\right)$ & $0.54 \times 10^{-5}$ & $2.9 \times 10^{-5}$ & $0.53 \times 10^{-5}$ & $8.1 \times 10^{-5}$ \\
\hline Latent heat of fusion $\left(\mathrm{J} \mathrm{m}^{-3}\right)$ & - & - & $21.8 \times 10^{8}$ & $9.4 \times 10^{8}$ \\
\hline Solidification shrinkage (pct) & - & - & 2.5 & 6.5 \\
\hline Thermal contraction coefficient $\left(\mathrm{K}^{-1}\right)$ & - & - & $12 \times 10^{-6}$ & $24 \times 10^{-6}$ \\
\hline
\end{tabular}

aluminum alloys, focusing on water cooling. The implications on quality problems are then discussed. Finally, optimal practices for the control of cooling in both processes are evaluated in the light of these fundamentals.

\section{HEAT TRANSFER DURING CONTINUOUS CASTING PROCESSES}

Although the continuous casting processes for steel and aluminum have many differences, as just introduced, there are also many similarities owing to the same primary goal of heat extraction from the molten and solidifying metal. The various heat-transfer phenomena acting on the surface of the strand during the continuous casting of steel and DC casting of aluminum alloys are schematically shown in Figures $2(a)^{[15]}$ and (b) ${ }^{[5]}$ respectively. Both processes involve a complex interplay of several heat-transfer mechanisms, which include convection of superheat in the liquid pool due to the momentum of the incoming metal, axial advection, and conduction through the moving solid shell; heat conduction from the solidification front to the colder outside surface of the metal; and heat transfer by convection to the mold (referred to as primary cooling), to the cooling water below the mold (referred to as secondary cooling), and to the bottom block (for DC casting only during startup).

However, the relative importance of these heat flow mechanisms is different, as evidenced by comparing the Péclet $(\mathrm{Pe})$ and Biot (Bi) numbers. The Péclet number is the ratio of advective to conductive heat flow given by $\mathrm{Pe}=\rho c_{p} V R / k$, where $\rho$ is density in $\mathrm{kg} \mathrm{m}^{-3}, c_{p}$ is specific heat in $\mathrm{J} \mathrm{kg}^{-1}$ $\mathrm{K}^{-1}, V$ is casting speed in $\mathrm{ms}^{-1}, R$ is size of the casting in meters, and $k$ is thermal conductivity in $\mathrm{W} \mathrm{m}^{-1} \mathrm{~K}^{-1}$. The low typical Pe range for DC casting of aluminum, i.e., $1.8<\mathrm{Pe}<$ 4.5 , indicates that axial conduction is as strong as advection. The Biot number is the ratio of convective to conductive heat flow given by $\mathrm{Bi}=h R / k$, where $h$ is the convective heattransfer coefficient active on the strand surface in $\mathrm{W} \mathrm{m}^{-2} \mathrm{~K}^{-1}$, and $\mathrm{R}$ is the conductive path length in meters. The relatively low value of $\mathrm{Bi}$ for $\mathrm{DC}$ casting, i.e., $2<\mathrm{Bi}<60,{ }^{[3]}$ indicates that the convective thermal resistance offered by the mold/cooling water contact at the ingot surface can greatly affect the heat transfer in the transverse direction.

In contrast, for continuous casting of steel, these numbers are much higher $(\sim 1000$ times for Pe and $\sim 10$ times for $\mathrm{Bi}$ ) owing to the higher casting speed and lower thermal conductivity. This indicates that the conductive component in the axial direction is negligible compared to the advective component, while the thermal resistance offered by conduction through the casting thickness dominates heat transfer in the

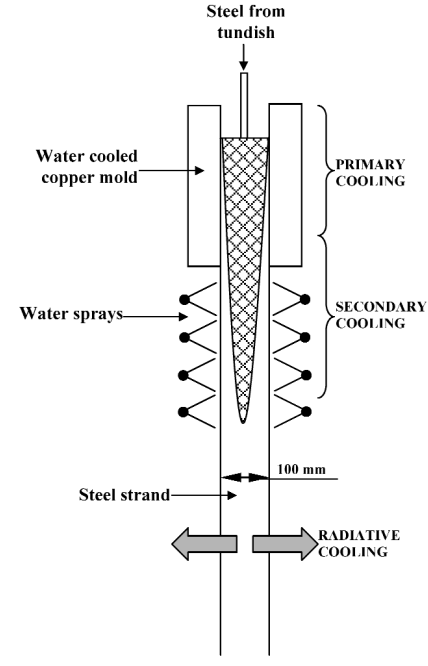

(a)

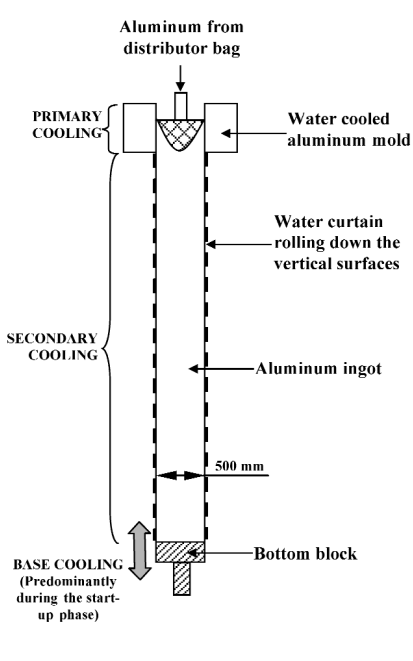

(b)
Fig. 2-Schematic of cooling processes, for $(a)$ continuous casting of steel ${ }^{[15]}$ and (b) DC casting of aluminum ${ }^{[5]}$.

transverse direction. The Biot and Péclet numbers also indicate the behavior of the liquid core depth profile. For $\mathrm{Bi}>$ 10 , the liquid pool shape lengthens almost linearly with increasing Pe and is almost insensitive to surface heat extraction rate. ${ }^{[16]}$ This indicates that the pool depth is proportional to the casting speed and inversely proportional to the metal conductivity, as noted earlier. The thickness of the semisolid (or mushy) zone and the hot tearing susceptibility are also sensitive to the Péclet number. ${ }^{[17]}$

The heat-transfer mechanisms discussed previously not only control the liquid pool shape, which has important implications for productivity, but also the magnitude of thermal stresses and strains generated in the strand owing to thermal contraction of the metal upon cooling. Changes in the temperature gradient across the solid shell due to an abrupt increase or decrease in the heat extraction rate causes differential thermal expansion in the solidifying metal and the generation of high thermal stress and strain. This can ultimately lead to internal or surface defects, which can severely compromise the quality of the cast product. Sections A through E discuss the different heat-transfer phenomena that occur during continuous casting.

\section{A. Mold (or Primary) Cooling}

Heat is supplied into a water-cooled mold by the continuous flow of incoming liquid metal during the continuous casting process. Heat transport in the liquid pool inside the 
mold and at the mold/metal interface affects both initial solidification at the meniscus and growth of the solid shell against the mold. The liquid metal usually enters the mold cavity through a ceramic entry nozzle. The angle and shape of the nozzle ports control the direction and turbulence of the liquid metal jets, which in turn control the flow pattern

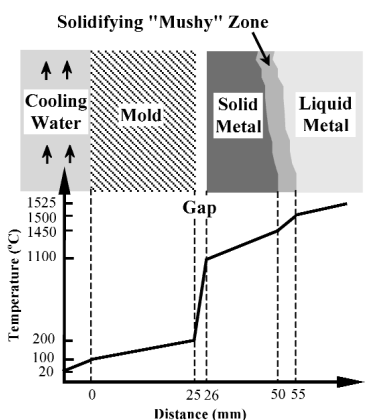

$\begin{array}{llll}\mathbf{R}_{\text {water }} & \mathbf{R}_{\text {mold }} & \mathbf{R}_{\text {air }} & \mathbf{R}_{\text {shell }} \\ \mathbf{R}_{\text {liq }}\end{array}$

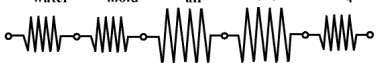

(a)

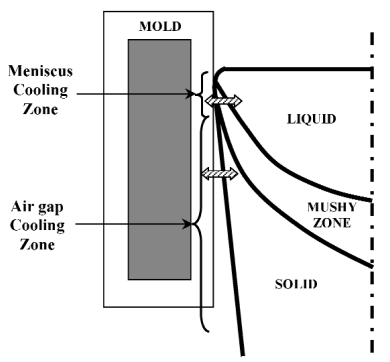

(b)

Fig. 3-Primary cooling during continuous casting: (a) temperature profile across the mold and shell (steel) and thermal resistances ${ }^{[19,23]}$, and (b) schematic of zones (aluminum) $)^{[18]}$.

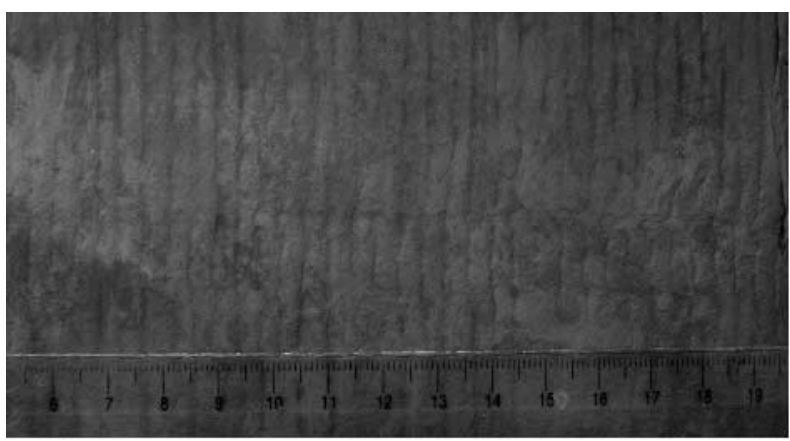

Low Carbon (Fe-0.05\%C) in the mold. The flow pattern controls stability and oscillation of the meniscus, which governs the surface shape, including the depth of depressions or oscillation marks, and associated defects. The flow pattern also governs the removal of superheat inside the shell where the jet impinges against the solidification front. To decrease the friction between the mold and strand, a lubricating medium is often added to the mold, which forms either a vapor or liquid layer, which prevents direct contact between the strand and mold walls.

Heat transfer at the metal/mold interface in continuous casting is referred to as mold or primary cooling. It varies with time, or distance down the mold, and can be subdivided into two regions of behavior: ${ }^{[18,19]}$ (1) mold/metal direct contact and (2) air gap cooling, as shown in Figure 3(a). In the beginning at the meniscus, the solidifying metal is in close contact with the mold, and the heat-transfer rate is very high. Specifically, peak heat fluxes can exceed $10 \mathrm{MWm}^{-2}$ in steel continuous casting ${ }^{[1,20]}$ and $1 \mathrm{MWm}^{-2}$ in aluminum DC casting $^{[2]}$. The latter process has smaller values for several reasons. Firstly, the roughness of the cast surface depends on alloy composition, as shown in Figure $4(0.25 \mathrm{~mm}$ for lowand high-carbon steels and $0.65 \mathrm{~mm}$ for peritectic grades) and $(0.05 \mathrm{~mm}$ for AA1050 and $0.45 \mathrm{~mm}$ for AA5182 aluminum alloys) ${ }^{[21]}$, and this will impact the heat flux in the mold. The DC cast surface likely has thicker oxide layers with different properties, which would increase the contact resis-

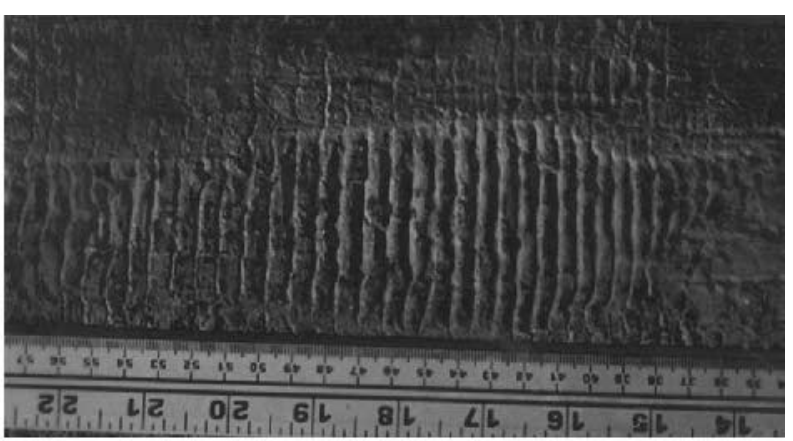

Peritectic (Fe-0.1\%C)

(a)

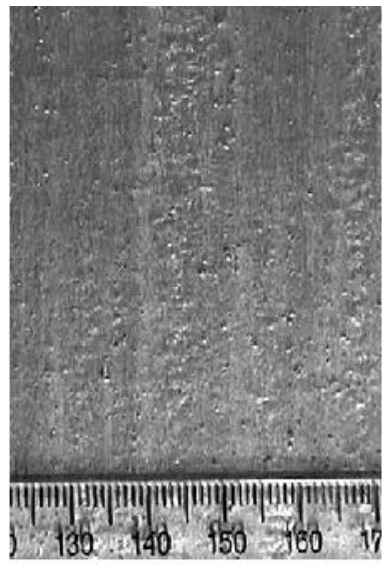

AA1050 (Al>99.5\%)

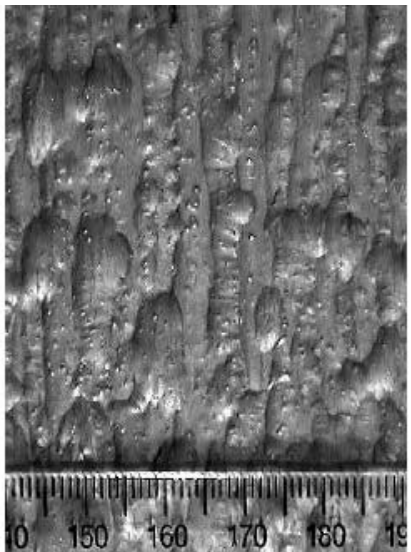

AA3004 (AI-1\%Mn-1\%Mg)

(b)

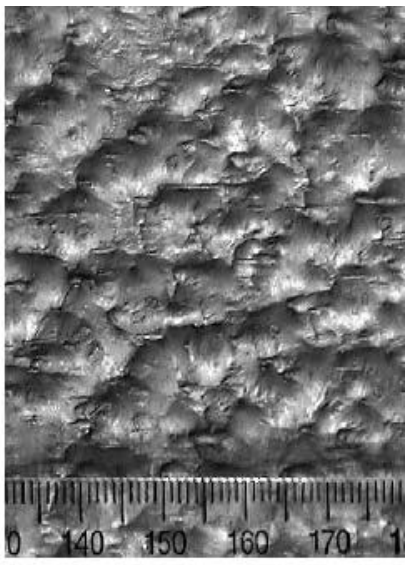

AA5182 (Al-4.5\%Mg)

Fig. 4-Strand surface morphologies for typical $(a)$ continuous cast steel and $(b)$ DC cast aluminum alloys ${ }^{[21]}$ (casting direction is to the right). 
tance of the interfacial gap. In addition, the aluminum shell conducts heat faster away from the peak heat flux region, which is also shorter in length. In steel continuous casting, the newly formed shell remains in relatively good contact with most of the 700-mm-long mold, owing to pressure from the internal liquid pool pushing the weak shell against the mold walls and intentional tapering of the mold walls to match the solidification shrinkage. In DC casting, however, the duration of this initial contact stage is quite brief, ending within $\sim 80 \mathrm{~mm}^{[2]}$ (depending upon the casting speed, alloy composition, and ingot geometry) of mold-metal contact.

Stage 1 ends with the formation of a significant air gap between the metal and mold as soon as the solid shell is strong enough to contract away from the mold faces. In steel continuous casting, this happens only near the corners. In the DC casting process, shrinkage of the thick shell away from the untapered mold produces gap formation around the entire perimeter. Once the gap has formed, the heat-transfer rate is greatly reduced,

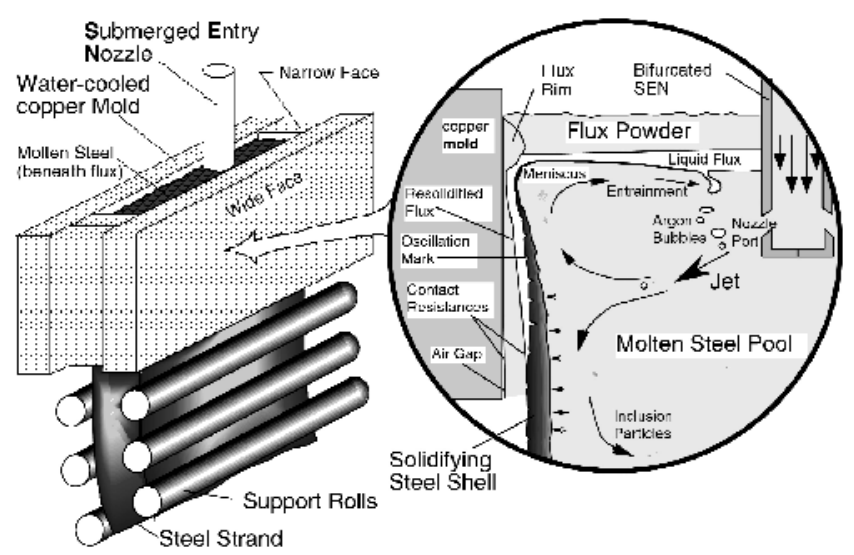

Fig. 5-Schematic of phenomena related to heat transfer inside and below the mold during continuous casting of steel. ${ }^{[25]}$ resulting in a reheating effect within the solid shell. Within stage 2, heat is conducted away from the shell via a series of thermal resistances ${ }^{[23]}$ : (1) air gap, (2) mold wall, and (3) mold/ cooling water interface, which are shown in Figures 3(a) $)^{[19,23]}$ and $(b)^{[18]}$. The interfacial gap comprises up to 85 pct of this resistance $^{[24]}$ and therefore controls the heat transfer inside the mold.

Figure $5^{[25]}$ illustrates more of the complex phenomena related to fluid flow and heat transport inside the mold during the continuous casting of steel. The flow pattern and turbulence in the pool is controlled by the nozzle port geometry and submergence depth. ${ }^{[26]}$ Argon gas is often injected to prevent nozzle clogging, ${ }^{[26]}$ and the resulting bubbles provide buoyancy that greatly affects the fluid flow pattern. These bubbles can also collect solid inclusions (such as alumina), which enter the metal pool through the nozzle and get entrapped in the solidifying shell, leading to internal defects in the final product. ${ }^{[27]}$ The jets from the nozzle carry superheat, which can sometimes melt through locally thin regions in the solidifying shell and cause breakouts. ${ }^{[27]}$ The jets also carry significant momentum, which controls the flow pattern and affects level fluctuations and meniscus solidification at the top surface. The corresponding flow phenomena during DC casting of aluminum are shown in Figure $6{ }^{[28]}$ Strong and irregular turbulent flow caused by direct or oblique entry of metal can create unfavorable (columnar) grain structures and uneven distribution of the alloying elements. ${ }^{[28]}$ These problems are overcome by surrounding the nozzle in a distribution bag, ${ }^{[29]}$ which diffuses some of the jet momentum and encourages a slower, more stable flow pattern that is also influenced by natural convection.

During the continuous casting of steel, heat transfer is complicated by the presence of mold flux. Its source is the mold powder, which is added to the free surface of the liquid steel to provide thermal and chemical insulation from the atmosphere and to absorb alumina inclusions. The powder sinters and melts, spreading over the meniscus and entering the air gap between the steel shell and mold wall. ${ }^{[30]}$ Some of the

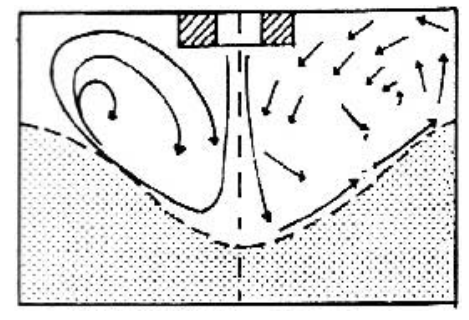

(a)

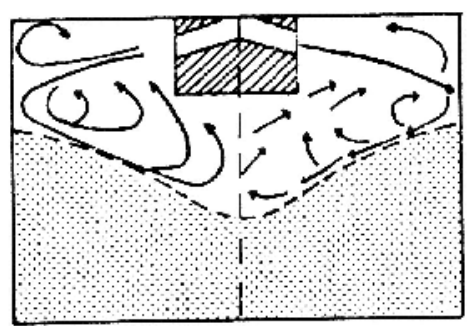

(c)

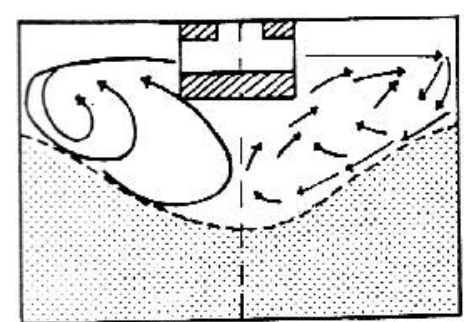

(b)

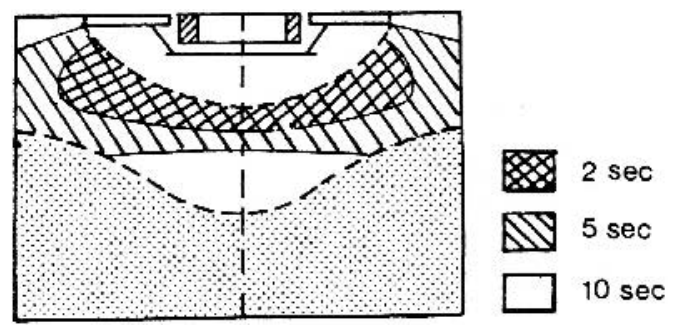

(d)

Fig. 6-Flow pattern (left side) and velocities (right side) and dye residence times (lower right) generated with different metal entry systems during DC casting: $(a)$ vertical entry, $(b)$ horizontal entry, $(c)$ oblique entry, and $(d)$ entry through a distribution bag. ${ }^{[28]}$ 
liquid flux/slag resolidifies against the cold mold wall creating a solid flux/slag rim (refer to Figure 5). Primary cooling at the meniscus is further complicated by the vertical oscillation of the mold, which prevents sticking of the shell to the mold and encourages entrainment of the molten flux into the mold/ shell interfacial gap. ${ }^{[23]}$ However, each oscillation cycle creates a transverse depression in the solidifying shell at the meniscus, called an oscillation mark, shown in Figure 4(a). Pressure from interaction with the flux rim at the meniscus can deepen these marks, ${ }^{[31]}$ according to the size of the rim. Unsteady level fluctuations and surface waves due to turbulence can disturb formation of these marks, creating surface defects, such as ripples or depressions in the final product, and are potential sites for transverse cracks. ${ }^{[23]}$ Deep oscillation marks increase the local gap resistance, thereby reducing the heat transfer to the mold and retarding the shell growth. ${ }^{[22]}$

The flux layers between the steel shell and mold wall facilitate uniform and usually lower heat transfer across the interfacial gap, compared with that of lubricating oil used in billet casting, which tends to produce an intermittent vapor gap. Heat transport across the gap naturally depends on the thermal properties and thickness of the flux layers. ${ }^{[19]}$ The gap size in turn depends on the oscillation mark and surface roughness profile, shrinkage of the solidifying shell, mold distortion, and the internal pressure exerted on the shell by the liquid metal. ${ }^{[32,33]}$ The gap formed by shrinkage of the shell away from the mold walls is largest where it begins at the corners, and spreads across the faces, which further complicates the heat-transfer process. ${ }^{[32]}$ The mold walls are routinely tapered to match the steel shrinkage in order to minimize air gap formation and to facilitate primary cooling. ${ }^{[34]}$

It is estimated that primary cooling during continuous casting of steel in the mold removes about 40 pct of the total superheat and about 30 pct of the total sensible heat. ${ }^{[11]}$ The surface heat-transfer coefficient typically decreases down the length of the mold from a peak value of 1500 to $2000 \mathrm{~W} \mathrm{~m}^{-2} \mathrm{~K}^{-1}$ at the meniscus to about 600 to $800 \mathrm{~W} \mathrm{~m}^{-2} \mathrm{~K}^{-1[22]}$ near the mold bottom. Many strand defects, such as transverse midface and corner cracks, can be directly attributed to factors that control primary heat transfer in the mold, including oscillation marks, improper mold lubrication, metal level fluctuations in the mold, and improper mold taper. ${ }^{[35,36]}$

Primary cooling in the mold accounts for only about $20 \mathrm{pct}$ of the total heat extracted ${ }^{[37]}$ from the solidifying ingot during the DC casting of aluminum alloys, but it still has a critical influence on the ingot surface microstructure and roughness. ${ }^{[38]}$ The heat extracted by primary cooling determines the surface temperature of the ingot at the point of exit from the mold. This subsequently influences the mode of boiling water heat transfer (film/nucleate boiling) below the mold, ${ }^{[39]}$ as discussed later (in Section B). The peak heat-transfer coefficient reported for aluminum contacting a chilled mold ranges from 2000 to 4000 $\mathrm{W} \mathrm{m}{ }^{-2} \mathrm{~K}^{-1} \cdot{ }^{40]}$ By comparison, in the air gap, the heat-transfer coefficient may be as low as $150 \mathrm{~W} \mathrm{~m}^{-2} \mathrm{~K}^{-1}$. ${ }^{[41]}$

In DC casting, the molten aluminum quickly freezes at the meniscus to form a thick solid shell, owing to the higher thermal conductivity, thermal diffusivity, and contraction coefficient of aluminum, relative to steel. As mentioned earlier, the low Péclet number in DC casting allows the chill water below the mold to remove heat from aluminum still inside the mold. Combined with the lack of mold taper, this causes the air gap to form very near to the meniscus and to extend over most of the mold. The extent of the solid shell inside the mold is referred to as the upstream conduction distance (UCD) ${ }^{[3]}$ If the meniscus level inside the mold is too high (refer to Figure $7(\mathrm{a})^{[42]}$ ), the larger UCD, and corresponding longer wider air gap, allows nonuniform reheating of the shell surface to cause surface composition variations due to macrosegregation, and even exudation, where solute penetrates through the local thin regions of the partially solidified shell. Subsequent freezing of solute droplets likely caused the lumps in Figure 4(b). Furthermore, local reduction of cooling rates produces unfavorable microstructures, such as large grain size and dendrite arm spacing. ${ }^{[28]}$

On the other hand, if the meniscus level is too low (refer to Figure $7(b)^{[42]}$ ), the smaller UCD can cause the meniscus to freeze. As new liquid flows over the frozen meniscus, a fold is formed and the ingot surface emerging from the mold has a rippled/lapped appearance, such as shown in Figure 4(b). These defects can ultimately lead to transverse cracking during subsequent processing, so an optimum UCD is always desired. Mold flux is not needed to protect the top surface in DC casting because the molten aluminum quickly oxidizes to form a protective layer of alumina. Instead, lubricating oil is applied to prevent sticking and also to reduce the amount of heat that flows through the mold wall, ${ }^{[3]}$ as also done in steel billet casting when surface quality is not a concern. ${ }^{[3]}$

To optimize heat transport inside the mold and also control the meniscus level, several strategies have been implemented in the aluminum industry. In open top molds, the metal level is lowered until folding occurs and then increased slightly. ${ }^{[3]}$ Insulating material is placed on hot top molds, and the UCD is allowed to coincide with a fixed point below the insulation. Surface quality has been reported to improve dramatically. ${ }^{[3]}$ A further improvement in controlling the meniscus contact point is achieved by air-assisted hot top mold systems. ${ }^{[43]}$ In the electromagnetic casting process, ${ }^{[44]}$ the mold is completely eliminated and electromagnetic force is applied to support the metallostatic head. Lack of contact between the mold and metal removes the problem of air gap formation, resulting in uniform cast microstructures. The

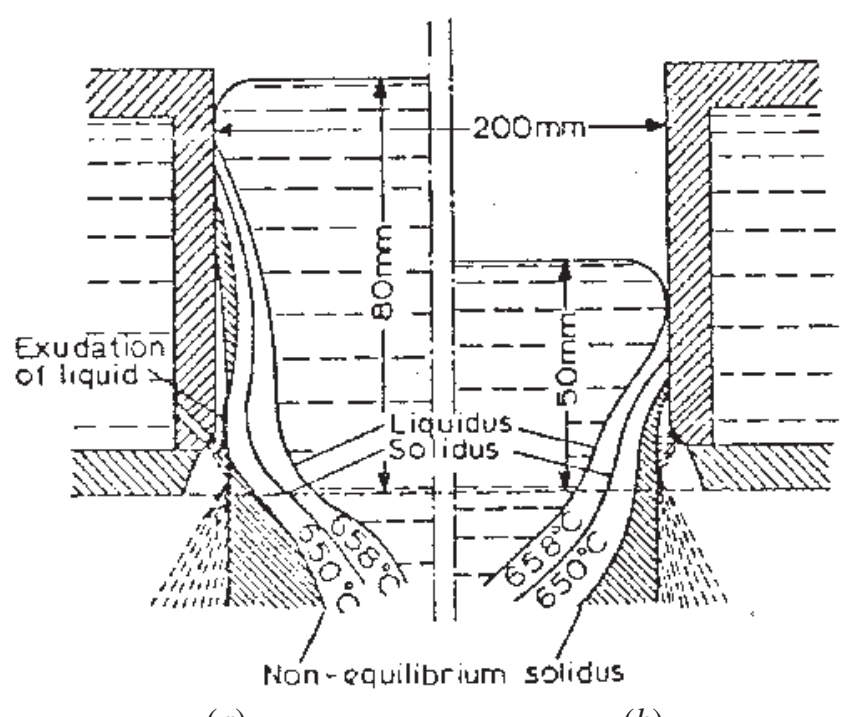

(a)

(b)

Fig. 7-Effect of (a) high and (b) low meniscus level on UCD and temperature contours in the mold region of DC casting. ${ }^{[42]}$ 
challenge then becomes maintaining stability of the unsupported meniscus by careful adjustment of the electromagnetic force to balance surface flows.

Another important factor controlling the extent of primary cooling is the effect of the cooling water on temperature and distortion of the mold itself. During the continuous casting of steel, cooling water flowing through the vertical slots in the copper mold extract heat from the mold and simultaneously control its temperature. The hot-face temperature of the mold indirectly affects the heat extraction rate by altering the properties of the interfacial gap. Mold variables directly control mold temperature, but the effects on primary cooling are more complex. For example, decreasing the velocity of the cooling water lowers the heat-transfer coefficient at the cold-face wall of the mold, causing mold temperature to increase. ${ }^{[22]}$ Increasing the temperature of the hot-face wall of the mold may partially melt the slag rim, leading to increased heat extraction from the mold. The effect is counterintuitive as primary cooling might increase with less cooling water. Impurities in the water can cause deposition of scale on the mold wall near the meniscus, causing mold temperature to increase. ${ }^{[22]}$ If the cold face temperature becomes too high, water may locally boil to form a stable film of air bubbles on the wall. This virtually stops heat removal and causes the mold to become dangerously hot.

The impact of mold cooling water on primary cooling during the DC casting of aluminum has not been explored, perhaps because the mold cooling water also has an even more important role below the mold. Research has mostly focused on the secondary heat extraction process of direct impingement of water on the hot metal surface exiting the mold.

\section{B. Water (or Secondary) Cooling}

After emerging from the mold, the continuous-cast strand is cooled by direct contact of water with the hot metal surface, as shown in Figures 2(a) and (b). This is referred to as secondary cooling. For steel casting, banks of nozzles located between contact rolls beneath the mold spray water to cool the moving metal strand. Usually, the spray nozzles are arranged into banks or cooling zones, assigned to the top and bottom surfaces of particular strand segments, ${ }^{[45]}$ as shown in Figure 8(a). The water is forced under high pressure as droplets that form a mist, which continuously impact upon the metal surface. Therefore, secondary cooling between each pair of rolls involves several different heat-transfer mechanisms operating in different subzones, which are illustrated in Figure 8(b). ${ }^{[25]}$ These are (1) roll contact cooling, (2) radiation and air convection from the bare strand surface just in the roll bite just above the spray region, (3) cooling due to spray water impingement, and (4) water convection cooling just below the spray region, where water runs down the strand and collects in the roll bite. Bulging of the steel shell caused by ferrostatic pressure can affect these heat-transfer subzones, especially near the roll bite and if the support rolls are spaced too widely apart. ${ }^{[46]}$

For aluminum casting, water jets emerge from holes located below the water-cooled mold and directly contact the metal surface, as shown in Figure 9(a). ${ }^{[21]}$ These jets form a continuous film, which wets the vertical ingot surfaces and rolls downward. Referring to Figure 9(a), ${ }^{[21]}$ two distinct subzones can be distinguished on the ingot surface: (a) the water impingement zone, where abrupt cooling occurs due to the direct contact with water, and (b) the streaming zone located below (a),

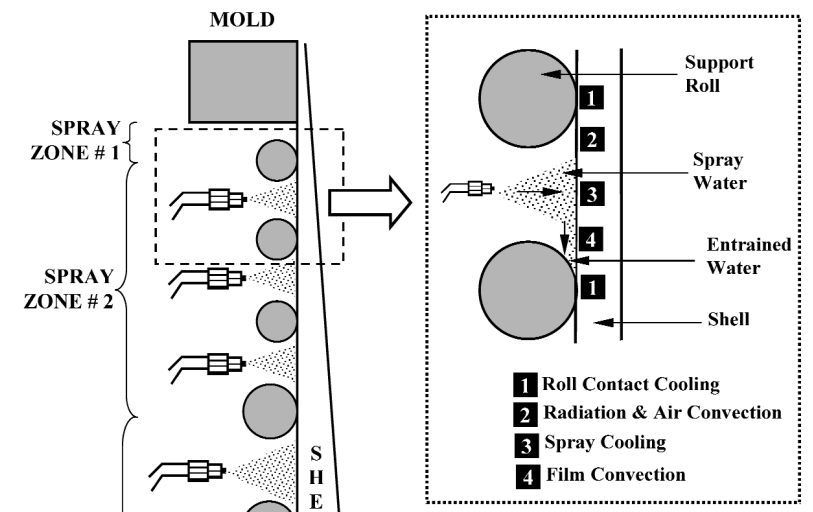

(b)

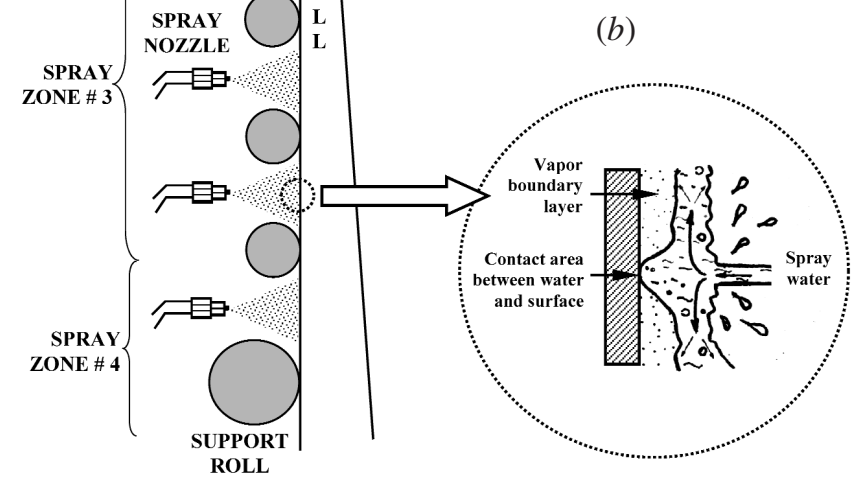

(a)

(c)

Fig. 8-Secondary cooling during continuous casting of steel: (a) typical arrangement of spray nozzles and support rolls ${ }^{[45]},(b)$ schematic of zones ${ }^{[25]}$, and $(c)$ detail of water spray-cooling process ${ }^{[47]}$.

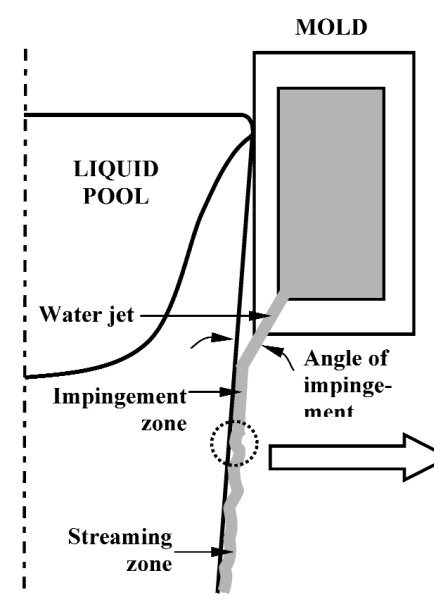

(a)

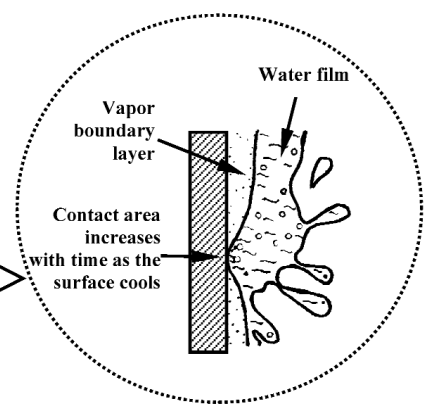

(b)
Fig. 9-(a) Secondary cooling regimes during DC casting of aluminum. ${ }^{[21]}$ (b) Detail of water film cooling process. ${ }^{[47]}$

where the heat flux diminishes as the water film loses momentum with increasing distance from the impingement point. The length of the water impingement zone is usually $\sim 10$ to $15 \mathrm{~mm}$, depending on the diameter of water holes at the base of the mold and angle of impingement.

Secondary cooling mechanisms provided by water spray for steel and water film for aluminum have distinctly different characteristics, ${ }^{[4]}$ as presented in Figures 8(c) and 9(b). In spray cooling (Figure 8(c)), water droplets impinge onto the very hot steel surface and vaporize instantaneously to create 
a boundary layer, which prevents the water from wetting the surface. Heat extraction is higher toward the center of the impingement region, where more of the high-speed droplets have enough momentum to penetrate the vapor layer. Extremely irregular flow conditions develop within the vapor boundary layer, and it eventually becomes wavy and is thinned out. The short contact times between the spray droplets and the strand surface increase with water velocity, owing to increased water momentum. Thus, the secondary cooling rate increases greatly with spray water flow rate, although it is almost independent of strand surface temperature. In contrast, under film cooling conditions (Figure 9(b)), water flows along the surface at a uniform velocity. As a result, the boundary layer of vapor between the water film and the metal surface tends to be thicker and unperturbed. However, as the metal surface cools, the vapor layer breaks down and the water film starts to contact the strand surface. The area of contact increases with decreasing strand surface temperature and is accompanied by a sudden increase in heat transfer. The cooling process is transient and is difficult to control.

In the continuous casting of steel, the purpose of secondary cooling is to maintain the heat extraction and solidification initiated in the mold with minimal change in surface temperature in order to avoid generating tensile stresses large enough to cause cracking. Only about 50 to 60 pct of the total heat content (including superheat, latent heat, and sensible heat) is removed by secondary cooling. ${ }^{[48]}$ However, this heat-transfer process is critical in DC casting as the chill water extracts about $80 \mathrm{pct}$ of the total heat content during the steady-state regime below the mold (the term "secondary" appears to be misplaced for the DC casting process while referring to cooling by chill water that originates in the mold).

The extraction of heat by cooling water is quite complex for both water spray and film cooling conditions because it is governed by the water boiling water phenomena, ${ }^{[49]}$ which depends greatly on temperature. As shown in Figure 10, four mechanisms of heat transfer ${ }^{[49]}$ can be distinguished when cooling water comes in contact with a hot metal surface. In order of increasing surface temperature, they are as follows.

1. Convective cooling at temperatures lower than $100{ }^{\circ} \mathrm{C}$

In this regime, heat transfer occurs via natural convection currents in the water film adhering to the metal surface, and the heat-transfer coefficient is very low.

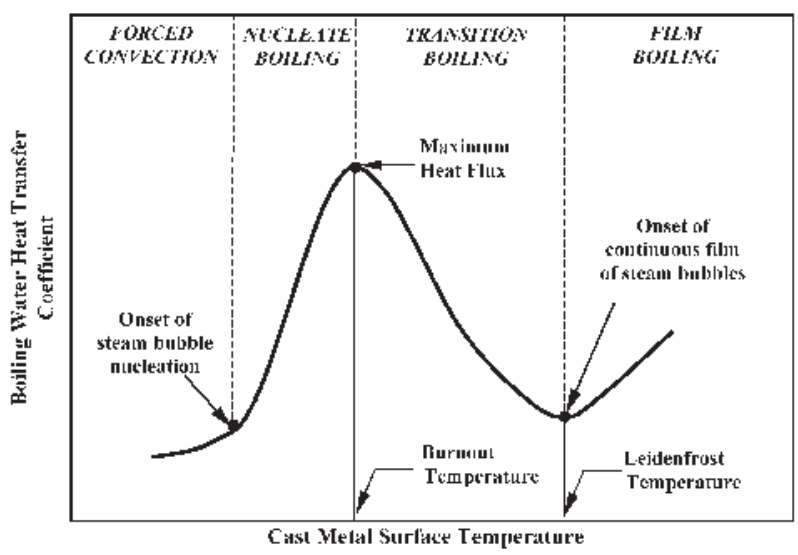

Fig. 10 - Generic boiling curve for water cooling indicating the different heattransfer regimes. ${ }^{[49]}$

\section{Nucleate boiling between $100{ }^{\circ} \mathrm{C}$ and burnout} temperature

As the surface temperature increases, bubbles of water vapor form on the metal surface, break off, and flow in the water film, eventually escaping from the free surface. The intensity of bubble formation and breakaway continues to increase as the surface temperature rises. This effect encourages good circulation in the water film causing the heat-transfer coefficient to increase rapidly until it reaches a maximum (referred to as the burnout point). The burnout temperature is about $500{ }^{\circ} \mathrm{C}$ to $700{ }^{\circ} \mathrm{C}$ for steel and $200{ }^{\circ} \mathrm{C}$ for aluminum, and increases with increasing water flow rate.

\section{Transition boiling between burnout and Leidenfrost} temperatures

Beyond the burnout point, the bubbles start sticking to the metal surface and a layer of vapor begins to form, which cuts down the circulation of heat. The heat-transfer coefficient decreases sharply with increasing temperature, as the vapor film continues to cover more of the metal surface, with everdecreasing amounts of metal surface exposed directly to water. When the metal surface is fully covered by a stable vapor film, the heat-transfer coefficient associated with the boiling curve reaches a minimum, which is referred to as the Leidenfrost point. The Leidenfrost temperature is about $700{ }^{\circ} \mathrm{C}$ to $1000{ }^{\circ} \mathrm{C}$ for steel and $300{ }^{\circ} \mathrm{C}$ to $500{ }^{\circ} \mathrm{C}$ for aluminum.

\section{Film boiling at high temperatures ( $>$ Leidenfrost temperature)}

At temperatures above the Leidenfrost point, heat is transferred by conduction through the stable vapor film. The heattransfer coefficient does not change much with temperature and is very low compared to that at the burnout point.

Two important points characterize the boiling curve in Figure 10. They are (1) the burnout temperature, which indicates the maximum heat flux (and heat-transfer coefficient), and determines the maximum ability of the water film to cool the metal surface by nucleate/transition boiling; and (2) the Leidenfrost temperature, which indicates the change in heattransfer mode from transition to vapor film boiling. Due to the strong corelationship between the heat-transfer coefficient and the surface temperature, heat extraction rates by secondary cooling can change rapidly with time and location near the Leidenfrost temperature. High heat-transfer rates associated with nucleate boiling can cause surface temperature to decrease rapidly. In contrast, the low heat-transfer rates associated with film boiling can allow surface temperature to increase. As a result, abrupt changes in the metal surface temperature can occur as the boiling phenomena are shifted from nucleate to film boiling and vice versa, depending on whether the Leidenfrost temperature is exceeded. Also, extreme variations of cooling can occur simultaneously at different locations on the metal surface, depending upon the local boiling behavior.

To optimize secondary cooling, the heat-transfer rate from the metal surface should produce a stable surface temperature that decreases monotonically. Film boiling is deliberately promoted during the secondary cooling process for the continuous casting of steel, in order to avoid the unstable surface temperatures and heat extraction rates that accompany nucleate/transition boiling, if the steel surface temperature drops too low. However, during the DC casting process, nucleate boiling is desired on the ingot surfaces during secondary cooling, in order 
to achieve high enough heat extraction rates under steady-state operations.

During startup of DC casting, it is a common industry practice to deliberately maintain a lower water flow rate in order to keep the ingot relatively hot for long enough to avoid intense cooling and stress buildup. This complicates the secondary cooling, as a portion of the water curtain may be ejected away from the ingot surface due to the formation of a stable film boiling layer beneath it. The heat-transfer rate is significantly lower within the region of water ejection, as there is little or no contact of the water film with the ingot surface. The result is a region with greatly reduced cooling at the hottest portion of the ingot surface below the impingement zone. As the ingot surface cools, however, the film boiling switches to transition and then to nucleate boiling. The water curtain is able to travel further down the ingot surface before it is ejected. Eventually, the surface is no longer hot enough to sustain film boiling; the stable film layer region collapses, and the cooling rate increases. The entire surface then has a stable water curtain with nucleate boiling heat transfer. This process is illustrated schematically in Figure $11^{[50,51]}$. The film boiling area appears as a visible "dome" on the ingot surfaces, with a parabola-shaped steam barrier profile demarcating the nucleate/transition and film boiling heat-transfer zones. This visual manifestation of water ejection, which is observed on the ingot vertical faces during the start-up phase, is illustrated in Figure 11(a $)^{[51]}$.

The various heat-transfer mechanisms associated with secondary cooling during continuous casting of both steel and aluminum are important because they determine the temperature gradients that develop inside the solidifying strand. Thus, they significantly influence the development of internal thermal stress/strain below the mold, and can aggravate defects generated inside the mold or introduce new defects.

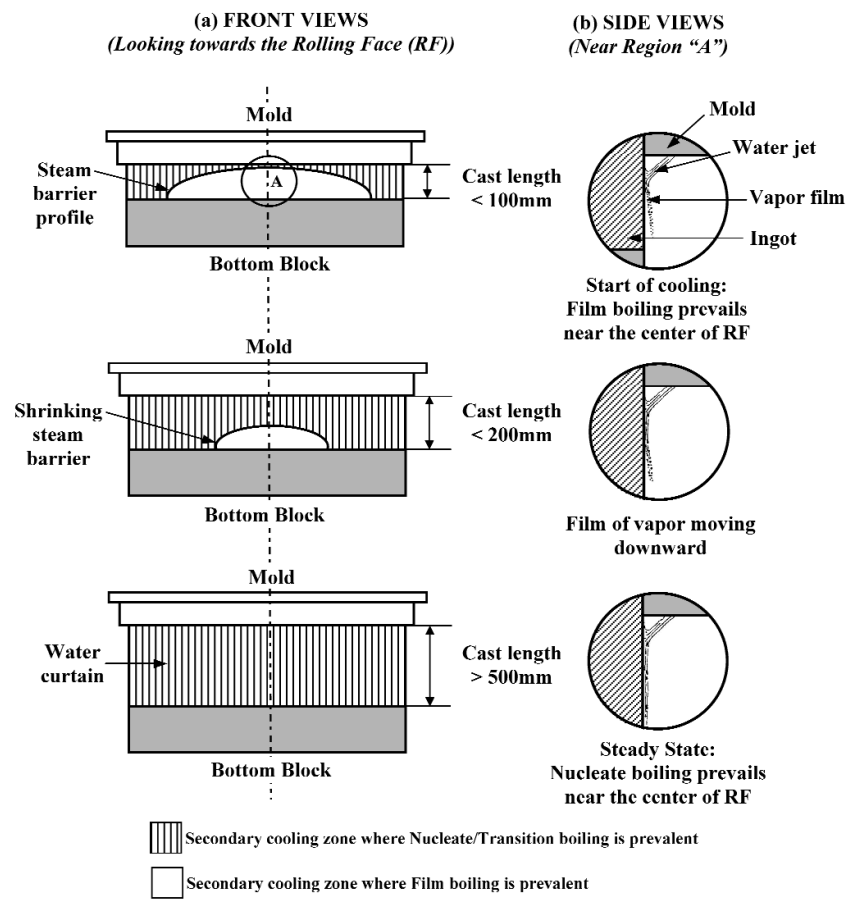

Fig. 11-Different boiling phenomena observed on DC cast ingot rolling surface during startup showing the evolution of the semielliptical-steam barrier region of film boiling in the hotter bottom-center region of the ingot surface, which collapses with time. ${ }^{[50,51]}$
Quality problems related to secondary cooling will be discussed in Section III.

\section{Radiative Cooling during Continuous Casting of Steel}

Beyond the spray zone region, the heat-transfer process simplifies to radiation and natural convection. The smaller cooling rate of radiative cooling results in reheating of the solidified strand, which causes the strand surface to expand. If the surface reheats too much before complete solidification, then plastic deformation of the hot austenitic shell and semisolid core may not be able to accommodate this expansion. This may cause subsurface hot-tear cracks to form at the solidification front. ${ }^{[15]}$ These cracks can cause internal segregation defects, or they may propagate through to the surface during later processing, such as rolling.

\section{Ingot Base Cooling during the DC Casting of Aluminum Alloys}

Secondary cooling also plays an important role in cooling the ingot base during the beginning of the start-up phase of the DC casting process. As the liquid metal enters the bottom block, the initial rate of heat transfer from the molten metal to the cold bottom block is extremely high. After a very short time, a small gap at the interface forms due to solidification shrinkage and the rate of heat-transfer drops. This gap remains relatively small until the ingot begins to withdraw from the mold and the base experiences a large macroscopic thermal distortion, called butt curl. This is aggravated by the slow cooling of the base, owing to the large gap and lack of water, combined with high thermal contraction of the vertical sides of the ingot, which experience higher heat extraction from the direct contact of a stable curtain. As the base continues to deform (or curl), water flowing down the sides may enter the bottom gap (water incursion) and enhance the heat transfer from the ingot base. ${ }^{[52,53]}$ This in turn will influence further deformation of the base. The details of the important interfacial heat-transfer processes active near the base of the ingot are schematically shown in Figure 12. ${ }^{[5]}$

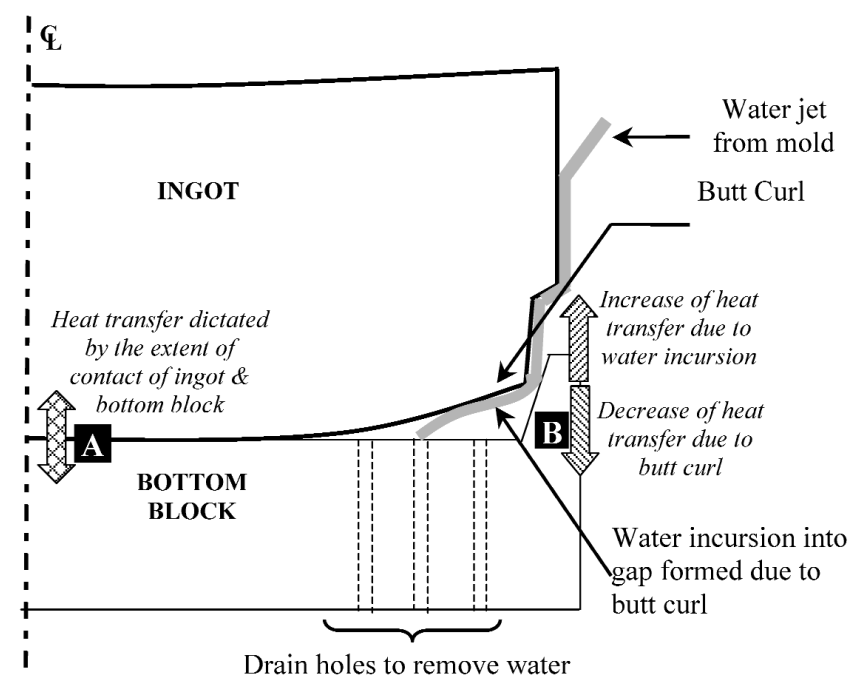

Fig. 12-Cooling and deformation of ingot base during the startup of DC casting, showing high contact near the center of the ingot (region A) and entry of secondary cooling water near the outer edges (region B). ${ }^{[5]}$ 


\section{E. Strand Cooling Behavior}

Figures $13(a)^{[25]}$ and $(b)^{[5]}$ compare typical surface temperature profiles along the strand length observed during the continuous casting of steel and aluminum alloys, respectively. Figure 13(b) also compares two aluminum ingots, produced by DC casting at different cooling rates (lower water flow rates were used for the hot cast). The primary and secondary cooling heat-transfer regimes can be easily identified in the cooling curves of both processes (refer to the cold cast in Figure 13(b)).

For steel, the extent of primary cooling is important, as it results in a temperature drop of $\sim 250{ }^{\circ} \mathrm{C}$, whereas for aluminum, the initial drop in the mold is $\sim 100{ }^{\circ} \mathrm{C}$. This is followed by reheating caused by the long air gap. Below the mold, the temperature during the continuous casting of steel varies over $\sim 100{ }^{\circ} \mathrm{C}$ over each roll pitch, as shown in Figure 13(a). Near the top of the caster, the greatest surface temperature drop occurs beneath each spray jet, while a tiny dip occurs at each small region of direct contact with a contact roll. Lower in the caster, the growing ferrostatic pressure increases the local heat extraction during roll contact, which makes the relative size of the spray and roll-contact dips become closer.

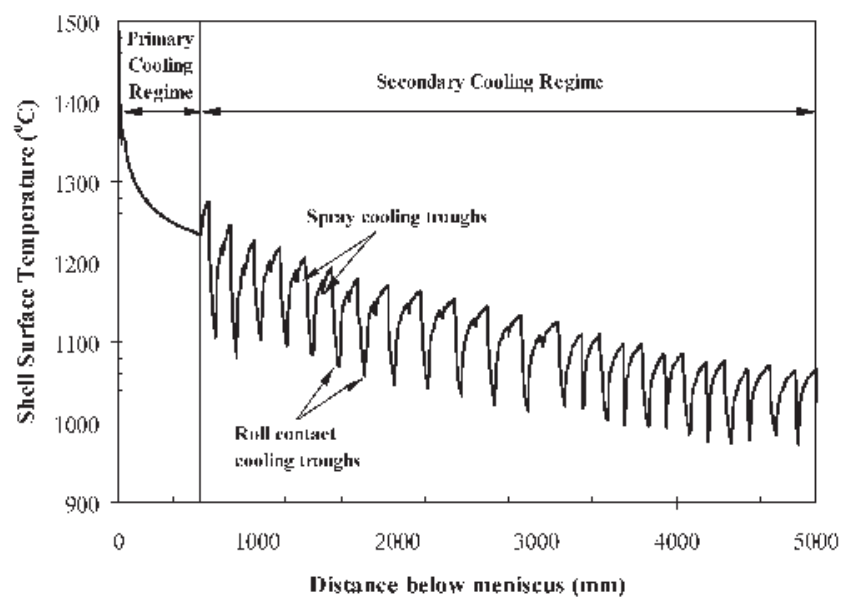

(a)

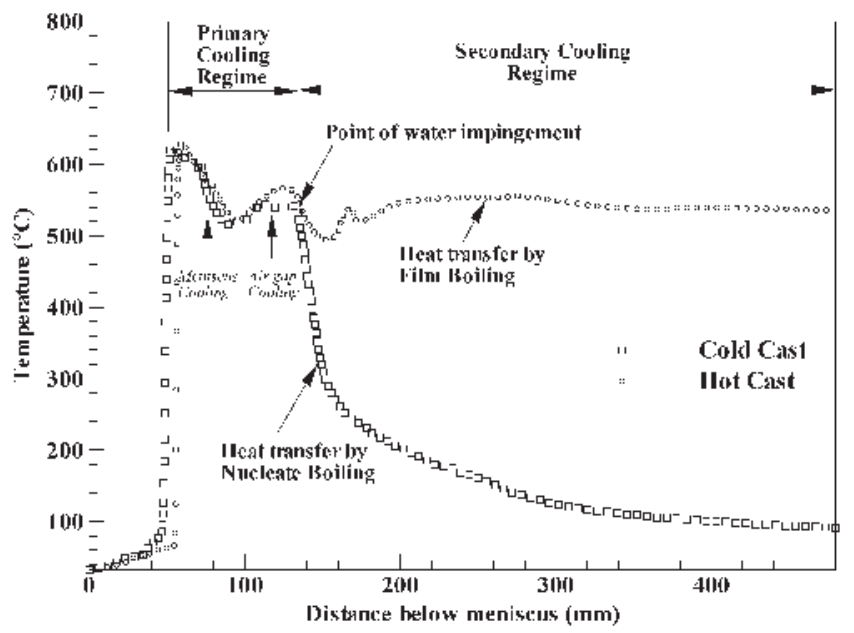

(b)

Fig. 13-Typical surface temperature profile and cooling regimes along strand length during continuous casting of $(a) \operatorname{steel}^{[25]}$ and $(b)$ aluminum ${ }^{[5]}$.
In contrast, during the DC casting process, Figure 13(b) shows that aggressive cooling from direct impingement of water at a high flow rate onto the metal surface causes the ingot surface to cool monotonically by $\sim 450{ }^{\circ} \mathrm{C}$ to $500{ }^{\circ} \mathrm{C}$ in only $300 \mathrm{~mm}$. With less water, the hot cast did not achieve sufficient cooling at the impingement zone, allowing the surface temperature of the ingot to exceed the Leidenfrost temperature. As a result, the heat transfer was in the film boiling range (refer to Figure 10), such that the rate of heat transfer was low and kept the solidifying shell dangerously hot near the solidus temperature for a long time. This also caused the macrodeformation of the ingot base to decrease from $\sim 50 \mathrm{~mm}$ for the cold cast to $\sim 6 \mathrm{~mm}$ for the hot cast.

\section{QUALITY PROBLEMS RELATED TO SECONDARY COOLING}

One of the most important considerations during the continuous casting process is the capability of attaining a defectfree slab or ingot. Two such quality issues are (1) hot tearing and cold cracking and (2) dimensional control (e.g., bulging of the steel shell and butt curl for aluminum ingots). These problems are directly attributed to tensile mechanical and thermal stresses/strains generated during the casting process. The variety of crack defects that affect continuous cast steel slabs and DC cast aluminum ingots are shown schematically in Figures $14^{[54]}$ and $15,{ }^{[55]}$ respectively.

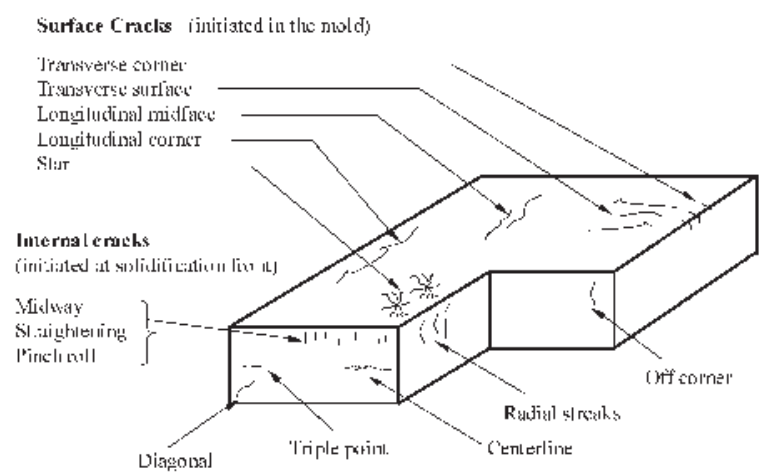

Fig. 14-Schematic of crack defects in continuous casting of steel. ${ }^{[54]}$

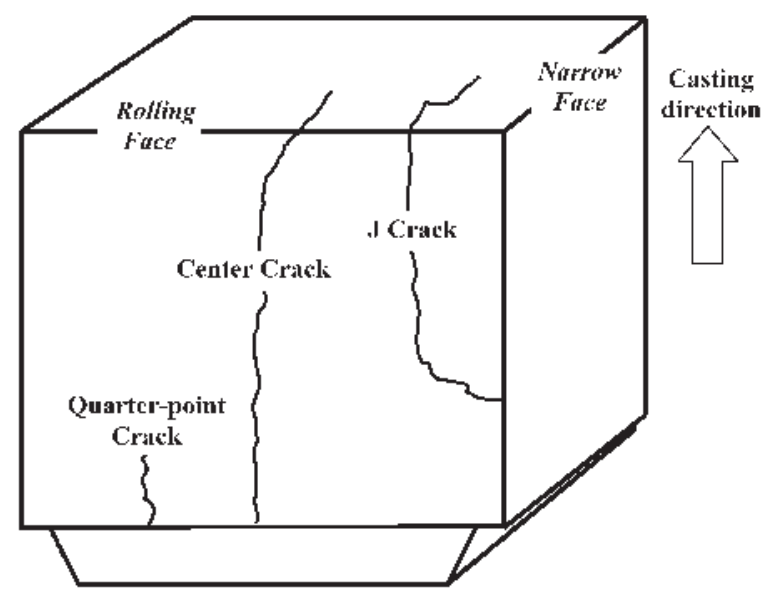

Fig. 15-Schematic of cold crack defects related to secondary cooling during DC casting of aluminum. ${ }^{[55]}$ 
Mechanically generated tensile strains, such as caused by inadequate mold lubrication or bending/straightening of the strand, usually act in the longitudinal direction and cause transverse cracking. During the casting process, rapid cooling can result in steep temperature gradients in the solidifying shell that can generate thermal strains as the shell expands and contracts. Sudden localized cooling can introduce tensile strains at the surface, whereas reheating can generate tensile strains at the solidification front. Thermal strains act predominantly in the transverse direction and are responsible for causing longitudinal cracks.

Cracks can form if the generated tensile strain locally exceeds the strain to fracture of the metal. In steel, different regions of low ductility have been reported. ${ }^{[54]}$ The most important one lies within $\sim 50{ }^{\circ} \mathrm{C}$ of the solidus temperature and is responsible for "hot tear" cracks. Aluminum experiences a similar rapid loss in strength and ductility between the solidus temperature and the coherency point (i.e., the temperature corresponding to about 90 pct solid fraction) ${ }^{[56]}$ Other mechanisms, involving sulfide, oxide, and nitride precipitates at the grain boundaries, operate in steel at lower temperatures, between $\sim 700{ }^{\circ} \mathrm{C}$ and $900{ }^{\circ} \mathrm{C},{ }^{[35,57]}$ and cause intergranular cold cracks.

Most cracks in steel slabs and billets are hot tears, due to the zone of low ductility near the liquid front. Internal cracks are often seen near the corners, at the centerline or diagonally between opposite corners. Surface cracks can appear near both midface and corner regions. Some cracks that form below $900{ }^{\circ} \mathrm{C}$ during the straightening of the shell have been attributed to the embrittlement caused by precipitation of AlN near the grain boundaries. ${ }^{[57]}$

In aluminum ingots/billets, hot tears or "presolidification" cracks can also form near the solidification front, when a tensile stress is imposed across partially solidified grains, and the surrounding liquid cannot fill the gap between the grains. Hence, these cracks are always intergranular. In contrast, cold cracks in aluminum ingots are initiated at temperatures below the solidus due to extremely high thermal stresses, and are always transgranular.

Brimacombe et al..$^{[48]}$ have summarized the causes of cracking problems in continuous cast steel. Improper secondary cooling practices contribute to many of these. Excessive spray cooling or insufficient spray length led to surface reheating, which induces tensile stresses beneath the surface, including the solidification front. This can cause internal cracks such as midway cracks in billet casting. Unsymmetrical cooling at the billet corners induces distortion and diagonal cracks. Excessive spraying of water can lead to rapid cooling and large tensile strains at the surface of slab castings, which can open small cracks formed in the mold. However, insufficient spray cooling below the mold can allow the slab to bulge out if the surface becomes too hot. This can lead to several defects, such as triple point cracks, midface cracks, midway cracks, centerline cracks and center segregation, as shown in Figure 14. Transverse surface and corner cracks begin in the mold, but can be opened by axial tensile stresses induced by spray cooling in slab casting, when the surface temperature is within the low-ductility range of $700{ }^{\circ} \mathrm{C}$ to $900{ }^{\circ} \mathrm{C}$. Secondary cooling practices that lead to excessive surface temperature fluctuations also aggravate these cracks, especially in this critical temperature range.

The thermal stresses and strains generated in the ingot during the transient start-up phase of the DC casting process can initiate hot tears and cold cracks, especially in highstrength aluminum alloys. ${ }^{[58]}$ Hot tears generally form between the quarter points of a rectangular ingot beneath the ingot surface. As shown in Figure $15,{ }^{[55]}$ cold cracks also originate at the ingot base and are located in the center half of the ingot width. High casting speeds tend to cause hot tears and low casting speeds increase the risk of cold cracks. ${ }^{[3]}$ The formation of hot tears has also been linked with the frictional forces between the ingot and mold (which is related to mold cleanliness) $)^{[42]}$, and the variability in cooling conditions during the transient start-up phase ${ }^{[59]}$. In addition to cracks, thermal stresses related to secondary cooling also generate macrodeformation of the ingot base or butt curl especially during startup. As reported by Droste and Schneider, ${ }^{[12]}$ the production problems related to butt curl include the following: runouts of the melt, cold shuts, reduced rigid standing (instability) of the ingot on the bottom block, and low recovery rates. Ultimately, if the magnitude of butt curl is excessive, the ingot bottom may have to be sawed off.

\section{FUNDAMENTAL INVESTIGATIONS OF WATER-COOLING PROCESSES}

\section{A. Primary Cooling}

Many fundamental experiments have been conducted to quantify convective heat transfer in confined channels, and they are summarized with empirical correlations. ${ }^{[60,61]}$ These relations have been applied to the continuous casting of steel, to quantify heat transfer in the mold. The heat-transfer coefficient between the sides of the water channels in the mold and the cooling water is calculated assuming turbulent flow through an equivalent diameter pipe, such as described by the following relationship: ${ }^{[60]}$

$$
h_{w}=\frac{k_{\text {water }}}{D}\left[5+0.015 \operatorname{Re}_{\text {waterf }}^{c_{1}} \operatorname{Pr}_{\text {waterw }}^{c_{2}}\right]
$$

where $D$ is the equivalent diameter of the water channel, $R e_{\text {waterf }}$ is the Reynolds number at the average of mold cold face and cooling water temperatures, $P r_{\text {waterw }}$ is the Prandtl number of water at the mold cold face temperature, and $c_{1}$ and $c_{2}$ are empirical constants. Other similar relationships are discussed elsewhere. ${ }^{[25,62]}$

Increasing the water flow in the mold increases the heattransfer rate and thereby decreases the mold temperature, leading to less mold distortion and fewer surface cracks. As discussed previously, the effect on mold heat flux is indirect, because mold heat flux is controlled mainly by the interfacial gap and thickness of the solidifying shell. This relationship is well appreciated in the continuous casting of steel, but has received little attention in DC casting molds.

\section{B. Secondary Cooling}

Experiments have been conducted to quantify heat transfer from water cooling and to establish boiling water curves (refer to Figure 10) in controlled laboratory experiments on small steel ${ }^{[48,63-68]}$ and aluminum ${ }^{[21,50,69-76]}$ samples, in plant measurements of secondary cooling in the continuous casting of steel ${ }^{[77]}$, and in DC casting of aluminum ${ }^{[78-81]}$. Generally, empirical relationships are developed by applying inverse heat-transfer analysis to the measurements recorded by 


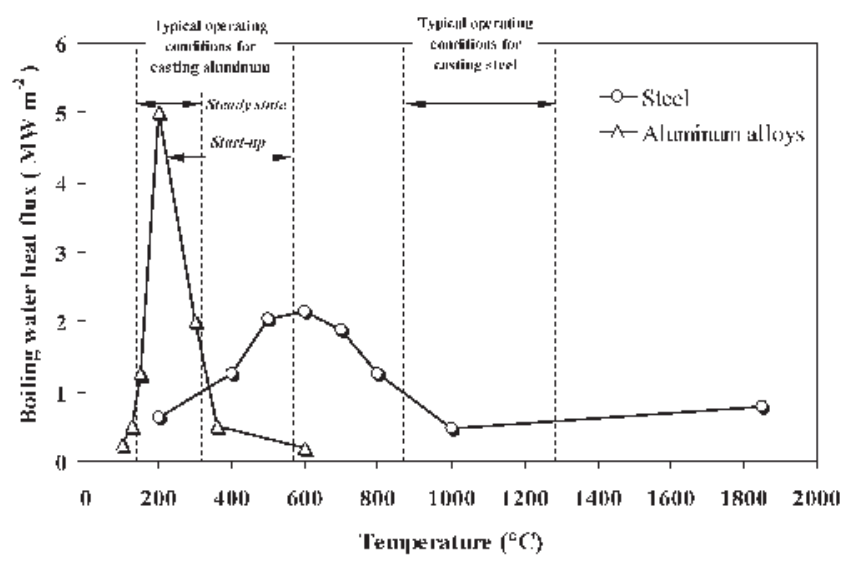

Fig. 16-Typical boiling curves and operating temperature ranges in the secondary cooling regime for continuous casting of steel ${ }^{[48]}$ and DC casting of aluminum ${ }^{[21]}$.

thermocouples embedded in the plate or casting. Figure $16^{[21,48]}$ compares typical boiling curves for steel and aluminum alloys obtained from such laboratory studies. Although the basic features of the boiling curves for the two systems are the same, the magnitude of maximum heat flux and Leidenfrost temperatures will differ due to the differences in thermophysical properties ${ }^{[47]}$ of the two metals as well as surface effects such as oxide layers and surface roughness. A heat input factor, $\sqrt{k \rho c_{p}}$, can be used to characterize heat transport to the metal/water interface. This factor is $\sim 1.5$ times greater for aluminum than for steel, indicating that heat flux can reach the interface more easily for aluminum than for steel.

Studies on secondary cooling and the boiling water curve for the continuous casting of steel reveal the following observations:

(1) Typical values of the maximum heat-transfer coefficient measured by different researchers ${ }^{[65,67,77]}$ lie between 2.0 and $3.0 \mathrm{~kW} \mathrm{~m}{ }^{-2} \mathrm{~K}^{-1}$ at the burnout temperature of $\sim 500{ }^{\circ} \mathrm{C}$ to $700{ }^{\circ} \mathrm{C}$.

(2) Within the desired surface temperature range of $900{ }^{\circ} \mathrm{C}$ to $1200{ }^{\circ} \mathrm{C}$ for spray cooling, the surface temperature of the strand has little impact on the spray heat-transfer coefficient. This relative lack of dependence clearly indicates that the heat-transfer mechanism is dominated by the convective heat transport occurring between the surface of the casting and a stable film of steam adhering to it (film boiling).

(3) Within the film boiling regime, the spray heat-transfer coefficient has a strong correlation with the water flow rate, as represented by the following empirical relationship: $:^{[67]}$

$$
h_{\text {spray }}=A \dot{W}^{c}
$$

where $h_{\text {spray }}$ is the spray heat-transfer coefficient (in $\mathrm{W} \mathrm{m}^{-2}$ $\left.\mathrm{K}^{-1}\right), A$ and $c$ are fitting parameters, and $\dot{W}$ is the water flow rate (in $\mathrm{L} \mathrm{m}^{-2} \mathrm{~s}^{-1}$ ). Typically, $A$ is 0.45 to 0.75 , and $c$ is 0.5 to $1.0 .^{[48]}$

(4) Increasing the discharge velocity of the spray droplets increases their momentum to break through the vapor layer, which suppresses stable film boiling, and thus increases the heat-transfer rate. ${ }^{[65]}$
(5) The Leidenfrost temperature is $\sim 1000{ }^{\circ} \mathrm{C}$ and increases sharply with increasing water flow rate, for the same reason.

(6) Increasing the temperature of the spray water has little influence on the heat-transfer coefficient, although one correlation shows a slight decrease. ${ }^{[67]}$

(7) The spray nozzle orientation has a small but important effect on the heat-transfer coefficient. ${ }^{[65]}$ Specifically, upward spraying is $15 \mathrm{pct}$ less than downward spraying. The heat-transfer coefficient decreases greatly with distance from the impingement point. As spray nozzles are oriented perpendicular to the strand surface, this decrease is roughly symmetrical.

From the secondary cooling studies conducted for DC casting of aluminum alloys, the following observations can be made.

(1) There is a general agreement between different measurement techniques that the maximum heat flux is between 1 and $5 \mathrm{M} \mathrm{W} \mathrm{m}^{-2}$, and the maximum heat-transfer coefficient lies between 40 and $50 \mathrm{~kW} \mathrm{~m}{ }^{-2} \mathrm{~K}^{-1}$. The corresponding burnout temperature is $\sim 200{ }^{\circ} \mathrm{C}$ to $250{ }^{\circ} \mathrm{C}$.

(2) Fundamentally, the operating temperature range of $220^{\circ} \mathrm{C}$ to $620^{\circ} \mathrm{C}$ is wider than for steel casting, extending down to the burnout temperature, so the ingot surface temperature has more effect on the heat transfer.

(3) The Leidenfrost temperature is $\sim 250{ }^{\circ} \mathrm{C}$ to $350{ }^{\circ} \mathrm{C}$ and increases with increasing water flow rate, in the same way as observed for steel. The heat-transfer coefficient at the Leidenfrost temperature is very sensitive to water flow rate at low flow rates. Thus, the water flow rate determines whether stable film boiling or water ejection will occur during the startup of DC casting. The Leidenfrost temperature can also be influenced by the water quality as well as the water temperature. ${ }^{[72]}$

(4) The oblique orientation of the water nozzle used in DC casting greatly affects the heat transfer. Because flow is directed downward along the ingot surface, the heat flux varies greatly with distance above or below its maximum at the impingement point. It drops significantly in the region of back flow above the impingement point. It decreases only gradually with distance below the impingement point as the water film loses momentum, and can be ejected from the surface by the formation of a stable vapor barrier.

(5) The rate of heat extraction is a strong function of metal surface temperature. This is shown in Figure $17^{[21]}$ as a function of temperature at the impingement point and in the streaming zone. This figure shows that the heat flux also depends strongly on the initial temperature of the surface when water is first added, which affects the transient coevolution of the water layer and the metal surface temperature.

(6) Under transient conditions, the rate of heat extraction has also been found to be influenced by alloy thermal conductivity, with higher conductivity material producing higher maximum heat fluxes for a given flow rate and surface temperature. ${ }^{[21]}$

(7) The morphology of the ingot surface emerging from the mold has a significant impact on the boiling curve behavior; with rougher surfaces exhibiting higher heattransfer rates. ${ }^{[21]}$ 


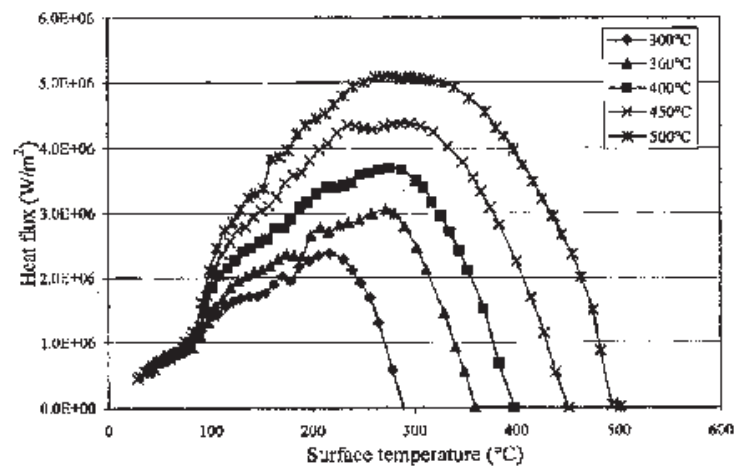

(a)

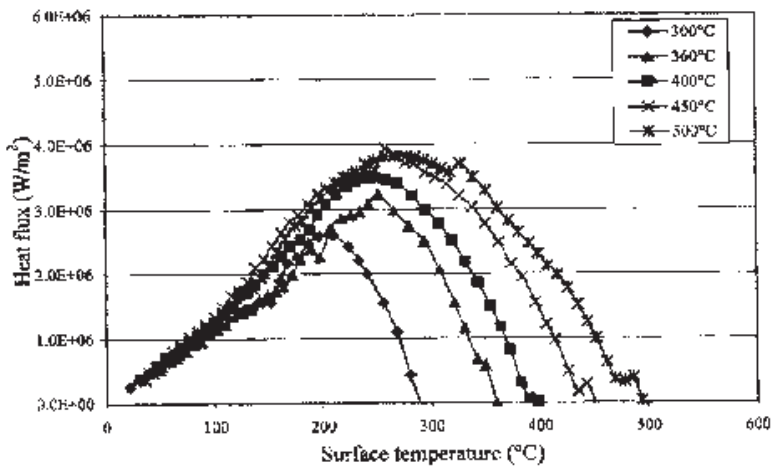

(b)

Fig. 17-Effect of initial sample temperature on calculated boiling curves ${ }^{[21]}$ (as-cast AA5182, water flow rate $=0.38 \mathrm{~L} \mathrm{~s}^{-1}$ ) for $(a)$ the impingement zone and $(b)$ the streaming zone.

\section{Model Applications}

The heat-transfer relations obtained from experimental measurements described in Section B allow the study of thermomechanical behavior in continuous casting processes using mathematical models. These relations can be implemented as Cauchy-type boundary conditions into finite-difference (FD) or finite-element (FE) based computational models to describe the cooling processes. These models can then predict the evolution of temperature, shell thickness, stress, and strain in the strand as it is cooled first in the mold and then during the secondary cooling zones.

Predicted results from some of these models are presented here to provide further insight into the heat-transfer phenomena acting during the continuous casting of steel and aluminum. For example, the distribution of heat removed during the continuous casting of steel can be calculated from a one-dimensional FD model, CON1D. ${ }^{[25]}$ Figure 18 shows the heat removed per unit area of the shell surface at different distances along the process. Most of the superheat is removed from the molten steel either inside the mold or near the mold exit. The total heat extracted per unit area of shell surface is similar on the wide and narrow faces. However, the narrow faces extract a larger fraction of the superheat because the bifurcated nozzles used in slab casting direct the superheat jets of molten steel onto the narrow faces. Secondary cooling is responsible for extracting the latent heat and some of the sensible heat from the solidifying shell. The latent heat is almost twice as large as the sensible heat extracted. Similar trends can be expected in the case of DC casting of aluminum.

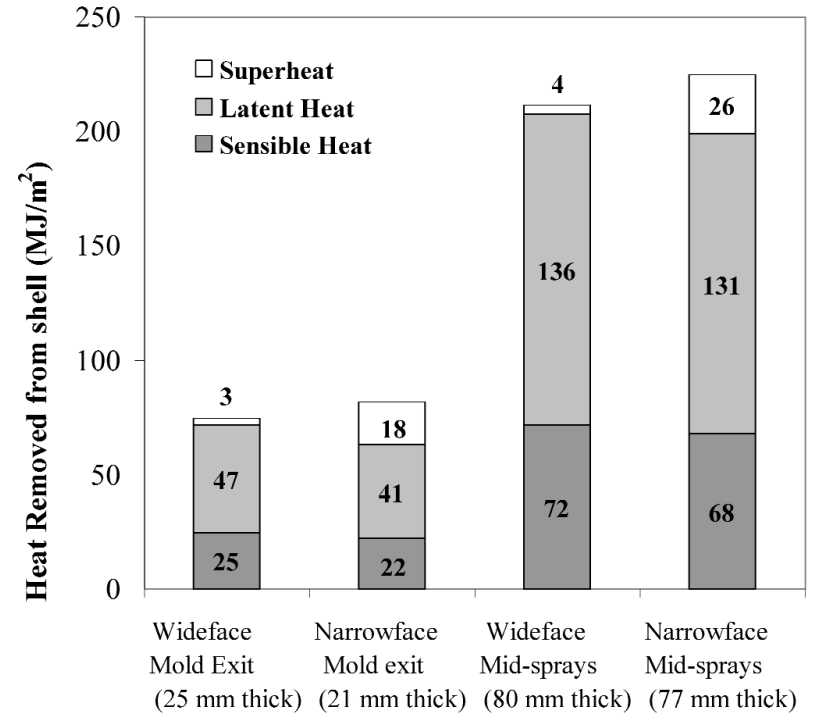

Fig. 18-Distribution of total heat removed from the shell at different locations during the continuous casting of steel. ${ }^{[25]}$

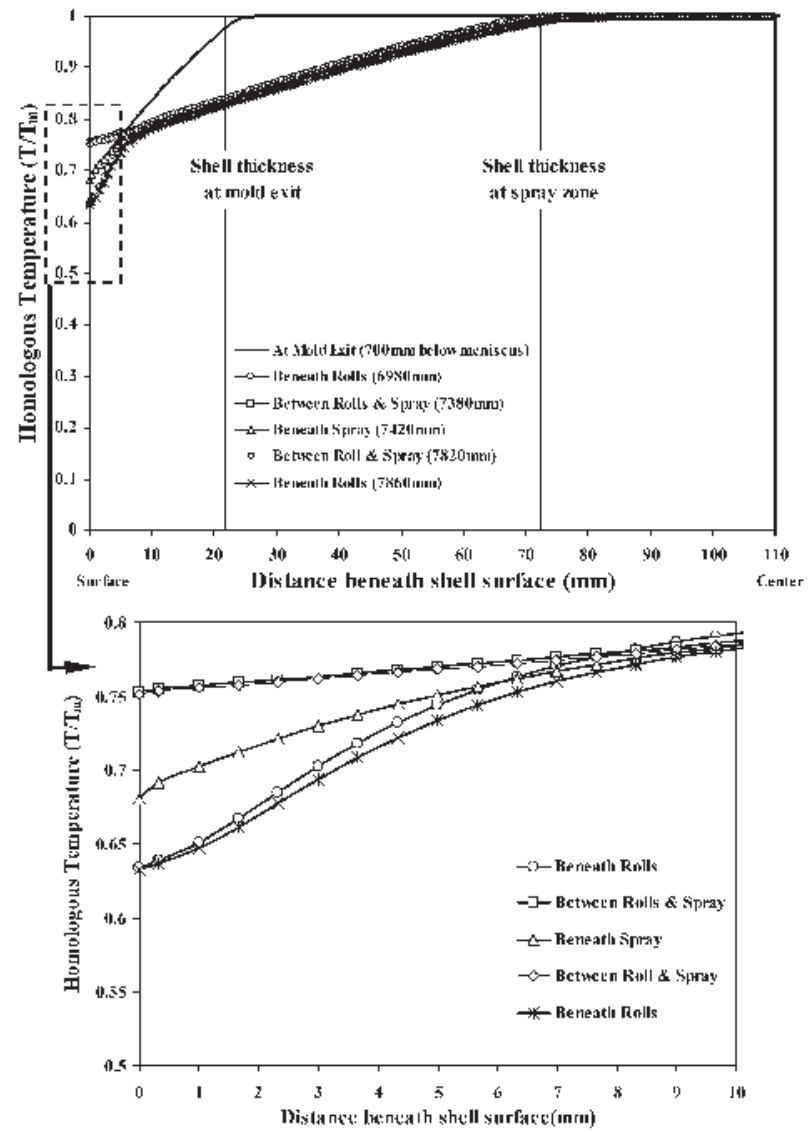

Fig. 19-Temperature profiles and shell thickness predicted in cross sections through the strand taken at mold exit and during secondary cooling for continuous casting of steel. ${ }^{[46]}$

The shell thickness predictions from a $2-\mathrm{D}^{[46]}$ and a $3-\mathrm{D}^{[2]}$ FE-based thermal model for casting steel and aluminum are shown in Figures 19 and 20, respectively. Profiles at the mold exit and in the secondary cooling are compared. Temperature 


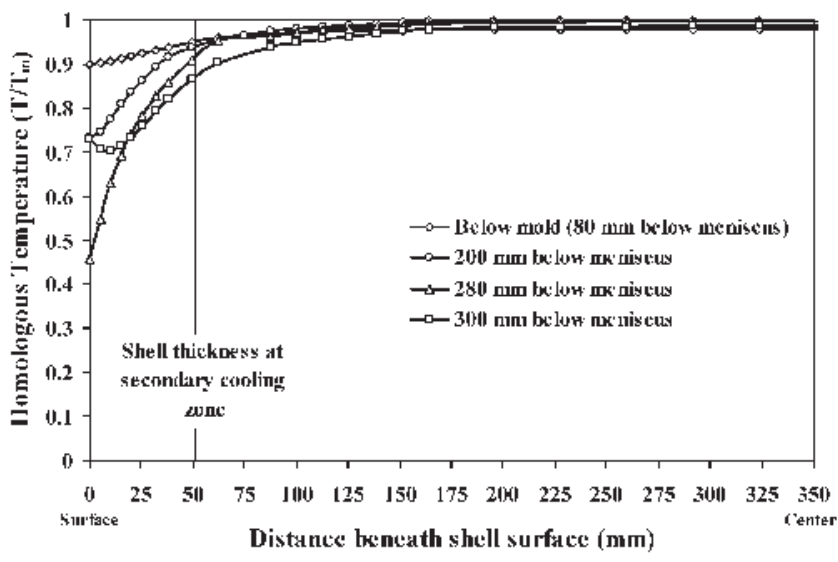

Fig. 20-Temperature profiles and shell thickness predicted in cross sections through the ingot during secondary cooling taken $\sim 375 \mathrm{~s}$ after startup for DC casting of aluminum. ${ }^{[2]}$

gradients through the shell are linear at the mold exit. The shell thickness at the mold exit is $\sim 20 \mathrm{~mm}$ for a typical case, as shown in Figure 19, and its surface temperature drops to 70 pct of the melting (liquidus) temperature, $T_{m}$ in absolute degrees (K). In contrast, Figure 20 shows that during the DC casting of aluminum, the solidifying shell may exit the short mold relatively hotter at 85 pct of $T_{m}$. This may leave the shell in a mushy state if the solidification range of the alloy is large, such as $\sim 100{ }^{\circ} \mathrm{C}$ for an AA5182 alloy. Shrinkage of the surface caused by subsequent cooling of the mushy shell by chill water can force the exudation of interdendritic liquid droplets and result in a very rough cast surface, as shown in Figure 4(b). For an AA1050 alloy, the solidification range is $<20{ }^{\circ} \mathrm{C}$, so the surface appearance is much smoother.

Inside the mold, the interfacial gap offers most of the resistance to heat extraction. However, beyond the mold exit, the resistance offered by the thickening shell in the secondary cooling zone becomes the rate-limiting factor in the process of heat removal from the strand for both continuous casting processes. It is, therefore, desirable that the secondary cooling process avoids any sudden increase or decrease in the surface heat extraction rate, in order to maintain a linear temperature gradient and avoid surface temperature variations that can generate local thermal strains and cracking problems. Figure 19 shows the predicted temperature distributions through the shell thickness in the secondary cooling regime for continuous casting of steel between a set of roll pitches. The steel shell is shown to experience rapid changes in the surface heat extraction rate while moving beneath the support rolls, as it travels between regions of intense and less-intense spray cooling. This greatly changes the thermal fields close $(\sim 10 \mathrm{~mm})$ to the surface.

Intensifying the spray cooling does not improve the rate of solidification, as indicated in Figure 19, by the almost unchanged linear temperature gradients deep inside the shell. It does, however, cause surface temperature variations that generate high local thermal strains near the shell surface that can aggravate cracking problems. Sharp drops in surface temperature can generate surface cracks, while the subsequent sharp increases can extend sub-surface cracks. Thermal cycling near the surface around the $\mathrm{Ar}_{3}$ temperature of steel is par-

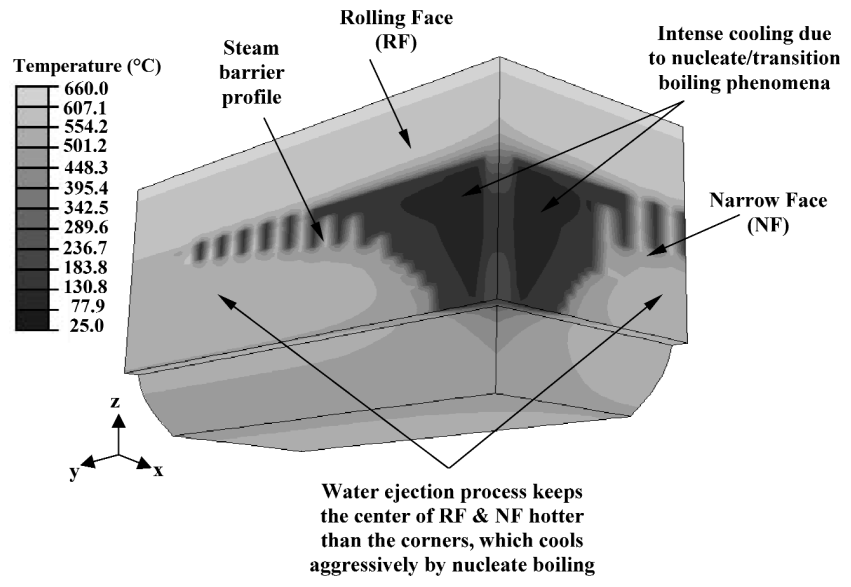

Fig. 21-Surface temperature contours on the narrow and rolling faces of a DC cast aluminum ingot at $\sim 375 \mathrm{~s}$ after startup. ${ }^{[2,5,82]}$

ticularly dangerous because it encourages precipitation of detrimental phases such as AlN and large internal stresses due to volume changes associated with the austenite-to-ferrite phase transformation.

During the start-up phase of the DC casting process, the aluminum shell reheats below the mold, as seen in Figure 20. This indicates the presence of a stable film boiling front on the rolling face, which reduces the heat-transfer coefficient and delays solidification. This effect is clearly indicated in Figure 21, which shows temperature contours predicted ${ }^{[2,5,82]}$ along the vertical faces of the ingot during the startup. A steam barrier exists on the vertical faces $20 \mathrm{~mm}$ below the mold exit owing to the ejection of water film (accompanied by generation of steam) from the ingot surface and along the barrier where the temperature is greater than the Leidenfrost temperature. This profile quantifies the schematic in Figure 11(a) and shows how the centers of the rolling and narrow faces of the ingot remain at a high temperature for a longer period of time than the ingot corners. This creates hot spots with high tensile strains just beneath the shell surface at the center of the vertical faces, which explains the initiation of hot tears that have been observed at this location. These observations underline the necessity for optimal design of the secondary cooling processes during the continuous casting of both steel and aluminum alloys, which ensure monotonic cooling of the shell and avoid the initiation and propagation of crack defects.

\section{OPTIMIZATION OF WATER COOLING}

From the previous discussion, it is evident that water cooling plays a critical role during the continuous casting of steel and the start-up phase of the DC casting process for aluminum alloys. Hence, optimizing the parameters that control the cooling process is necessary to generate defect-free castings. Mold geometry and operating variables can be designed to control the hot face temperature of the mold at the meniscus, in order to control primary cooling of the shell. The water channels in steel continuous casting molds are routinely configured to optimize heat transfer between the cooling water and mold faces. For example, reducing the channel 
depth, increasing the spacing, and decreasing the width of the water channels leads to higher hot face temperatures. ${ }^{[22]}$ Hot face temperature also decreases with higher water velocity. Some operations adjust water velocity online in order to control mold hot-face temperature.

The task of optimizing secondary cooling is easier for steel continuous casting than for DC casting, because cooling is governed by film boiling phenomena so the heat-transfer coefficient is relatively independent of the strand surface temperature. Relationships describing the variation of heat flux with nozzle type, nozzle-to-nozzle spacing, spray water flow rate, and distance of the spray nozzles from the strand surface are given in the literature. ${ }^{[48,65,77,83-85]}$ Under steadystate conditions, spray practices can be designed to achieve cooling conditions that prevent defects. Specific techniques include "plateau cooling" ${ }^{[68]}$ and air-water mist cooling ${ }^{[86,87]}$. The purpose of plateau cooling is to keep the surface temperature of the strand in the spray-cooling zone always above $700{ }^{\circ} \mathrm{C}$, and to avoid reheating from below this temperature. This procedure can prevent cracks, which are associated with the loss of ductility in steel at temperatures between $700{ }^{\circ} \mathrm{C}$ and $900{ }^{\circ} \mathrm{C}$. Air-water mist cooling has helped to provide more uniform cooling in both casting and transverse directions, and hence avoids cracks by minimizing the localized temperature fluctuations caused by the undercooling and overcooling associated with water droplet spray jets. Furthermore, automatic control systems are available in the industry ${ }^{[45,88]}$ to adjust the sprays according to changes in casting speed and thereby optimize secondary cooling conditions for transient conditions as well. These control systems make use of online computational models to ensure that each portion of the shell experiences the same cooling conditions.

Unfortunately, in DC casting, relatively little fundamental work has been done to optimize the water-cooling phenomena to control the final ingot quality. Despite increased automation, the control of cooling conditions is difficult due to the many complex inter-related effects. The mold, chill water, and bottom block simultaneously cool the ingot surfaces. This combined interplay determines the surface temperature of the ingot exiting the mold, which in turn governs the boiling water-cooling conditions (film/nucleate boiling) that dictate secondary cooling. Recent practices have focused on varying bottom block shape and filling rate, casting speed, and water flow conditions in order to lower the cooling intensity during startup of DC casting, which lowers thermal stress and the accompanying butt curl. Combining low cooling water volume with high casting speed during startup reduces base deformation for some alloys. ${ }^{[12]}$ Inflatable ingot wipers have also been used to remove cooling water from the ingot surface and thus decrease the secondary cooling. ${ }^{[89]}$ If carried too far, however, these practices can cause excessively high local surface temperatures that can lead to cracks and breakouts. Butt curl can also be reduced by solidifying a thick bottom shell, which bends to a lesser extent upon direct impingement of water. This can be achieved by appropriate bottom block design ${ }^{[90]}$ or by using longer filling times ${ }^{[91]}$. Additional stateof-the-art water-cooling systems include Alcoa's $\mathrm{CO}_{2}$ injection $^{[92]}$, Wagstaff's Turbo process ${ }^{[93]}$, and Alcan's Pulse Water technique ${ }^{[94]}$. Both Alcoa and Wagstaff techniques use gases to promote film boiling. The gas bubbles in the water film quickly adhere to the ingot surface, generating an insulating layer that reduces the heat-transfer coefficient. The
Alcan process applies rotary valves to turn the cooling water on and off during the start-up phase. Thus, the average heat flux is lowered and the surface temperature of the ingot becomes high enough to trigger film boiling.

With the development of sophisticated commercial FE codes and more powerful computers, mathematical models based on fundamental principles can be developed to predict the temperature distribution and stress/strain fields in the solidifying strand during the continuous casting process. This approach can minimize the immense experimental efforts traditionally required to optimize the process. To achieve this, it is critical that these mathematical tools capture all of the complexity of the physical phenomena active during the industrial process. Such models validated by industrial measurement can prove to be powerful tools for process optimization. Also, these thermal models coupled with a stress model and an appropriate hot tearing/cracking criterion can be effectively used to develop permissible process windows for casting defectfree products.

Over the past several decades, mathematical modeling has been extensively used in the steel industry to control both primary and secondary cooling processes. Models such as CASIM, DYNCOOL, and DYSCOS have been adopted by the industry for online process control. ${ }^{[45]}$ The University of Illinois at Urbana-Champaign $\left(\mathrm{CON}_{1} \mathrm{D}^{[25]} / \mathrm{CON} 2 \mathrm{D}^{[95]}\right.$ ) and L'Ecole des Mines de Paris ${ }^{96]}$ have developed FE-based programs to study the fundamentals of the complex but industrially-relevant phenomena in the mold and spray-cooling regimes.

Thermomechanical modeling tools to design and optimize the DC casting process have been developed at several industry and university consortia (such as VirCAST ${ }^{[97]}$ and EMPACT ${ }^{[37]}$ in Europe and SECAT ${ }^{[98]}$ in the United States) using FE packages such as MARC ${ }^{[99]}$ (at CORUS, Netherlands and Péchiney, France ${ }^{[37]}$ ), ABAQUS ${ }^{[100]}$ (at EPFL-Lausanne, Switzerland ${ }^{[14,44]}$ ), and $\operatorname{ALSIM}^{[101]} / \operatorname{ALSPEN}^{[102,103]}$ (at Institute for Energy Technology, and Hydro Aluminum, Norway ${ }^{[104]}$ ). National laboratories in the United States (Albany Research Center, Oregon, Argonne National Laboratory, Illinois, and Oak Ridge National Laboratory, Tennessee) and at the University of Kentucky (Lexington, KY) have also collaborated recently to develop mathematical models to study ingot stress crack formation and butt deformation ${ }^{[105]}$ and to reduce aluminum ingot scrap. In Canada, University of British Columbia and Alcan International Ltd. are also jointly pursuing modeling activities to generate hot tearing criteria for the DC casting process. ${ }^{[5]}$

\section{SUMMARY AND CONCLUSIONS}

Continuous casting processes for steel and aluminum alloys have different process design and operating parameters, owing to their differences in thermophysical properties such as melting point, thermal conductivity, thermal contraction coefficient, and solidification shrinkage. However, the fundamental heat-transfer processes characterizing the removal of superheat, latent heat, and sensible heat are similar. Both mold and water play significant roles in dictating the complex cooling phenomena under both transient and steadystate conditions.

This article shows how water cooling governs the temperature of the metal strand, and how asymmetrical or localized 
cooling problems can cause defects leading to high rejection rates and low productivity. Specific observations include the following.

1. Empirical relations to describe cooling in the water channels are well established and used to optimize primary cooling in the mold during the continuous casting of steel. Hot face temperature influences interfacial heat transport at the meniscus, which greatly affects surface quality. Perhaps the optimization of mold water cooling and the related control of mold taper and mold distortion, which have been applied so successfully in the steel industry, could also help to improve the DC casting mold for aluminum and other nonferrous alloys.

2. In the case of continuous casting of steel, vapor film boiling dominates the heat extraction mechanism during spray cooling. As a result, the boiling water heat-transfer coefficient is independent of strand surface temperature, and heat extraction is stably controlled by water flow rate. In contrast, transition/nucleate boiling often arises during DC casting to cause aggressive cooling of the ingot surfaces. However, film boiling is desired during the transient cast start-up phase to reduce the effect of butt curl. Effects such as water ejection and water incursion coupled with the rapidly changing ingot surface temperature during the transient phase can significantly complicate the heat-transfer process. As a result, the process is extremely difficult to control.

3. Empirical relationships describing the variation of boiling water heat-transfer coefficient with spray nozzle type, nozzle separation, distance of the nozzle from the surface of the strand, and water flow rate have been established for secondary cooling of steel. However, the effects of surface finish and water quality/contamination have not been investigated. For DC casting of aluminum alloys, correlations for boiling water curves have been developed mainly under steady-state conditions. Only a few studies for certain specific aluminum alloys are available, which can describe the boiling water heat transfer during the transient phase at which time the heat-transfer coefficient can be a strong function of ingot surface temperature, water flow rate, distance from the impingement point, and the impingement point temperature.

4. Secondary cooling should be designed to cool the strand surface in a controlled, monotonic manner, in order to avoid severe temperature gradient fluctuations that cause cracks. Developments such as plateau cooling, air-mist cooling, and online process control with mathematical models has helped to improve secondary cooling in continuous casting of steel. A variety of processes have been developed for DC casting of aluminum.

5. Despite decades of plant trials and increased process automation, quality problems related to water cooling such as butt curl and hot tear cracks still nag the DC casting industry. Different proprietary "recipes" are currently used by different aluminum companies to change casting variables as a function of time and alloy during startup. There is recent recognition of the need for wellvalidated, fundamentally based thermomechanical mathematical models of the DC casting process to aid further improvements, including the optimization of water-cooling practices.

\section{ACKNOWLEDGMENTS}

The authors thank the Natural Sciences and Engineering Research Council (NSERC), Canada for providing financial support for J. Sengupta and the Continuous Casting Consortium at the University of Illinois at Urbana-Champaign.

\section{LIST OF SYMBOLS}

\begin{tabular}{|c|c|c|}
\hline Symbol & Description & Unit \\
\hline A & fitting parameter & - \\
\hline$\sqrt{k \rho c_{p}}$ & heat input coefficient & $\mathrm{J} \mathrm{m}^{-2} \mathrm{~K}^{-1} \mathrm{~s}^{-0.5}$ \\
\hline $\mathrm{Bi}$ & Biot number & - \\
\hline$c$ & fitting parameter & - \\
\hline$c_{1}, c_{2}$ & empirical constants & - \\
\hline$c_{p}$ & specific heat & $\mathrm{J} \mathrm{kg}^{-1} \mathrm{~K}^{-1}$ \\
\hline$h$ & $\begin{array}{l}\text { convective heat-transfer } \\
\text { coefficient }\end{array}$ & $\mathrm{W} \mathrm{m} \mathrm{m}^{-2} \mathrm{~K}^{-1}$ \\
\hline$h_{\text {spray }}$ & $\begin{array}{l}\text { spray water heat-transfer } \\
\text { coefficient }\end{array}$ & $\mathrm{W} \mathrm{m}{ }^{-2} \mathrm{~K}^{-1}$ \\
\hline$h_{w}$ & $\begin{array}{l}\text { convective heat-transfer } \\
\text { coefficient between } \\
\text { mold and cooling water }\end{array}$ & $\mathrm{W} \mathrm{m}^{-2} \mathrm{~K}^{-1}$ \\
\hline$k$ & thermal conductivity & $\mathrm{W} \mathrm{m}{ }^{-1} \mathrm{~K}^{-1}$ \\
\hline$k_{\text {water }}$ & $\begin{array}{l}\text { thermal conductivity } \\
\text { of water }\end{array}$ & $\mathrm{W} \mathrm{m} \mathrm{m}^{-1} \mathrm{~K}^{-1}$ \\
\hline $\mathrm{Pe}$ & Peclet number & - \\
\hline$P r_{\text {waterw }}$ & $\begin{array}{l}\text { Prandtl number of water } \\
\text { at the mold cold face } \\
\text { temperature }\end{array}$ & - \\
\hline$R$ & size of casting & $\mathrm{m}$ \\
\hline$R e_{\text {waterf }}$ & $\begin{array}{l}\text { Reynolds number at average } \\
\text { of mold cold face and } \\
\text { cooling water temperatures }\end{array}$ & - \\
\hline V. & casting speed & $\mathrm{ms}^{-1}$ \\
\hline$\dot{W}$ & water flow rate & $\mathrm{L} \mathrm{m}^{-2} \mathrm{~s}^{-1}$ \\
\hline$\rho$ & density & $\mathrm{Kg} \mathrm{m}^{-3}$ \\
\hline
\end{tabular}

\section{REFERENCES}

1. C. Li and B.G. Thomas: Proceedings of the Brimacombe Memorial Symposium, Vancouver, BC, Oct 1-4, 2000, TMS, Warrendale, PA, 2000, pp. 595-611.

2. J. Sengupta, S. Cockcroft, D. Maijer, M. Wells, and A. Larouche: Metall. Mater. Trans. B, 2004, vol. 35B, pp. 523-40.

3. J.F. Grandfield and P.T. McGlade: Mater. Forum, 1996, vol. 20, pp. 29-51.

4. B.G. Thomas: in The Encyclopedia of Materials: Science and Technology, Volume II, eds., K.H.J. Buschow, R. Cahn, M. Flemings, B. Ilschner, E.J. Kramer, S. Mahajan, (D. Apelian, subject ed.) Elsevier Science Ltd., Oxford, UK, 2001, pp. 1595-1599; online http://www.elsevier.com/ mrwclus/15/show/Main.htt

5. J. Sengupta: Ph.D. Thesis, University of British Columbia, Vancouver, 2002.

6. J.B. Wiskel: Ph.D. Thesis, University of British Columbia, Vancouver, 1996.

7. E.K. Jensen: Light Metals 1980, TMS, Warrendale, PA, 1980, pp. 631-42.

8. W.K.J. Jones, D. Xu, J.W. Evans, and D.P. Cook: Light Metals 1999, TMS, Warrendale, PA, 1999, pp. 841-45.

9. J.R. Davis: ASM Specialty Handbook: Aluminum and Aluminum Alloys, ASM INTERNATIONAL, Materials Park, OH, 1994.

10. P.W. Baker and P.T. McGlade: in Light Metals 2001, J.L. Anjier, ed., TMS, Warrendale, PA, 2001, pp. 855-62.

11. X. Huang, B.G. Thomas, and F.M. Najjar: Metall. Mater. Trans. B. 1992, vol. 23B, pp. 339-56. 
12. W. Droste and W. Schneider: in Light Metals 1991, E.L. Rooy, ed., TMS, Warrendale, PA, 1991, pp. 945-51.

13. J. Sengupta, S. Cockcroft, D. Maijer, M. Wells, and A. Larouche: $J$. Light Met., 2002, vol. 2 (3), pp. 137-48.

14. J.-M. Drezet and M. Rappaz: Metall. Mater.Trans. A, 1996, vol. 27A, pp. 3214-24.

15. J.K. Brimacombe, I.V. Samarasekera, and J.E. Lait: in Continuous Casting Vol. II: Heat Flow, Solidification and Crack Formation, Ed. J.K. Brimacombe, I.V. Samarasekera, and J.E. Lait, ISS-AIME, Warrendale, PA, 1984, pp. 1-8.

16. S.C. Flood, P.A. Davidson, and S. Rogers: in Modeling of Casting, Welding and Advanced Solidification Processes VII, M. Cross and J. Campbell eds., The Minerals, Metals and Materials Society, Warrendale, PA, 1995, 801-10.

17. M. Zheng and L. Katgerman: in Proceedings of the 22nd Ris $\phi$ International Symposium on Materials Science, Roskilde, Denmark, A.R. Dinesen, M. Eldrup, D. Juul Jensen, and S. Linderoth, eds., 2001, Ris $\phi$ International Laboratory, Denmark, pp. 455-60.

18. M. Trovant and S. Argyropoulos: in Light Metals 1997, R. Huglen, ed., TMS, Warrendale, PA, 1997, pp. 927-31.

19. Y. Meng and B.G. Thomas: Metall. Mater. Trans. B, 2003, vol. 34B, pp. 707-25.

20. J. Birat, M. Larrecq, J. Lamant, and J. Petegnief: in Mold Operation for Quality and Productivity, A.W. Cramb and E. Szekeres, ed., ISS, Warrendale, PA, 1991, pp. 3-14.

21. M.A. Wells, D. Li, and S.L. Cockcroft: Metall. Mater. Trans. B, 2000, vol. 32B, pp. 929-39.

22. R.B. Mahapatra, J.K. Brimacombe, and I.V. Samarasekera: Metall. Mater. Trans. B, 1991, vol. 22B, pp. 875-88.

23. B.G. Thomas, D. Lui, and B. Ho: in Sensors and Modeling in Materials Processing: Techniques and Applications, Proceedings of the TMS Annual Meeting, Orlando, FL, Feb 9-13, 1997, TMS, Warrendale, PA, 1997, pp. 117-42.

24. I.V. Samarasekera and J.K. Brimacombe: Can. Metall. Q., 1979, vol. 18, pp. 251-66.

25. Y. Meng and B.G. Thomas: Metall. Mater. Trans. B, 2003, vol. 34B. pp. $685-705$.

26. H. Bai and B.G. Thomas: Metall. Mater. Trans. B, 2001, vol. 32B. pp. 269-84.

27. B.G. Thomas and S.P. Vanka: NSF Design, Service, Manufacturing and Industrial Innovation Research Conf., Puerto Rico, 2002.

28. S. Engler, W. Schmitz, M.S. Ji, and A. Weiss: in Proceedings of Symposium on Advances in Continuous Casting and Research Technology, Cairo, Egypt, 1992, Abington Publishing, UK, 1992, 192-204.

29. G. Gruen, A. Buchholz, and D. Mortensen: Light Metals 2000, R.D. Peterson, ed., TMS, Warrendale, PA, 2000, pp. 573-78.

30. B.G. Thomas, A. Moitra, and R. McDavid: Iron and Steelmaker (USA), 1996. vol. 23 (4). pp. 57-70.

31. M.M. Wolf: BHM 2000, 2000, vol. 145 (7), pp. 270-75.

32. R. Bommaraju, J.K. Brimacombe, and I.V. Samarasekera: ISS Trans., 1984, pp. 95-105.

33. B.G. Thomas: Iron \& Steelmaker (ISS Trans.), vol 16 (12), 1989, 53-66.

34. B.G. Thomas: Metall. Mater. Trans. B, 2002, vol. 33B, pp. 795-812.

35. J.K. Brimacombe and K. Sorimachi: Metall. Mater. Trans. B, 1977, vol. 8B, pp. 489-505.

36. J.K. Brimacombe, F. Weinberg, and E.B. Hawbolt: Metall. Mater. Trans. B. 1979. vol. 10B. pp. 279-92.

37. J.M. Drezet, A. Bughardt, H.G. Fjaer, and B. Magnin: Mater. Sci. Forum, 2000, vol. 329-330, pp. 493-500.

38. W. Schneider and W. Reif: in Proceedings of Symposium on Advances in Continuous Casting and Research Technology, Cairo, Egypt, 1992, Abington Publishing, UK, 1992, 173-90.

39. D.C. Weckman and P. Niessen: Metall. Mater. Trans. B, 1982, vol. 13B, pp. 593-602.

40. K. Ho and R.D. Pehlke: Metall. Mater. Trans. B, 1985, vol. 16B, pp. 585-94.

41. Y. Nishida, W. Droste, and E. Engler: Metall. Mater. Trans. B, 1989, vol. 17B, pp. 833-44.

42. A.A. Nofal: in Proceedings of Symposium on Advances in Continuous Casting and Research Technology, Cairo, Egypt, 1992, Abington Publishing, UK, 1992, 205-18.

43. R. Mitamura, T. Ito, Y. Takahashi, and T. Hiraoka: in Light Metals 1998, R. Huglen, ed., TMS, Warrendale, PA, 1978, pp. 281-91.

44. J.-M. Drezet: Ph.D. Thesis, Ecole Polytechnique Federale de Lausanne, Lausanne, Switzerland, 1996.
45. R.A. Hardin, K. Liu, A. Kapoor, and C. Beckermann: Metall. Mater. Trans. B, 2003, vol. 34B, pp. 297-306.

46. L. Yu: Ph.D. Thesis, University of Illinois, Urbana-Champaign, Urbana, IL, 1996.

47. H.M. Tansi and G.E. Totten: Proceedings of the 3rd International Conference on Quenching and Control of Distortion, Prague, Czech Republic, 1999, 50-61.

48. J.K. Brimacombe, P.K. Agarwal, S. Hibbins, B. Prabhakar, and L.A. Baptista: in Continuous Casting Vol. II: Heat Flow, Solidification and Crack Formation, J.K. Brimacombe, I.V. Samarasekera, and J.E. Lait, eds., ISS-AIME, Warrendale, PA, 1984, pp. 109-23.

49. L.C. Burmeister: Convective Heat Transfer, John Wiley \& Sons, Inc., New York, 1983, pp. 567-77.

50. A. Larouche, Y. Caron, and D. Kocaefe: in Light Metals 1998, B. Welch, ed., TMS, Warrendale, PA, 1998, pp. 1059-64.

51. G.P. Grealy, J.L. Davis, E.K. Jensen, P.A. Tondel, and J. Moritz: in Light Metals 2001, J.L. Anjier, ed., TMS, Warrendale, PA, 2001, pp. 813-21.

52. W. Droste, J.-M. Drezet, G.-U. Grun, and W. Schneider: in Continuous Casting, K. Ehrke and W. Schneider, eds., Wiley-VCH, New York, NY, 2000, pp. 177-83.

53. J. Sengupta, D. Maijer, M.A. Wells, S.L. Cockcroft, and A. Larouche: in Light Metals 2001, J.L. Anjier, ed., TMS, Warrendale, PA, 2001, pp. 879-85.

54. B.G. Thomas, J.K. Brimacombe, and I.V. Samarasekera: Trans. Iron Steel Soc., 1986, vol. 7, pp. 7-20.

55. J. Du, B.S.-J. Kang, K.-M. Chang, and J. Harris: in Light Metals 1998, B. Welch, ed., TMS, Warrendale, PA, 1998, pp. 1025-29.

56. L.J. Colley: Master's Thesis, University of British Columbia, Vancouver, 2003.

57. J.K. Brimacombe: in Continous Casting Vol. II: Heat Flow, Solidification and Crack Formation, J.K. Brimacombe, I.V. Samarasekera, and J.E. Lait, eds., ISS-AIME, Warrendale, PA, 1984, pp. 199-214.

58. J.E. Jacoby: 5th Australasian Asian Pacific Conference on Aluminum Cast House Technology, TMS, Warrendale, PA, 1997, 245-51.

59. J.B. Wiskel and S.L. Cockcroft: Metall. Mater. Trans. B, 1996, vol. 27B, pp. 129-37.

60. C.A. Sleicher and M.W. Rousse: Int. J. Heat Mass Transfer, 1975, vol. 18 (5), pp. 677-83.

61. F.W. Dittus and L.M.K. Boelter: Univ. California Public. Eng., 1930, No. 2, pp. 443-61.

62. L.C. Burmeister: Convective Heat Transfer, 1st ed., John Wiley \& Sons, New York, NY, 1983.

63. M. Mitsutsuka: Tetsu-to-Hagané, 1968, vol. 54, pp. 1457-71.

64. M. Shimada and M. Mitsutsuka: Tetsu-to-Hagané, 1966, vol. 52, p. 1643.

65. E. Mizikar: Iron Steel Eng., 1970, vol. 47, pp. 53-60.

66. R. Alberny, A. Leclerq, and J. Basilis: Circulaire d'Informatio-techniques, vol. 3 (315), 1973, 763-76.

67. T. Nozaki, J. Matsuno, K. Murata, H. Ooi, and M. Kodama: Trans. Iron Steel Inst. Jpn., 1978, vol. 18, pp. 330-38.

68. E. Bolle and J.C. Moureau: Int. Conf. on Heat and Mass Transfer Metallurgical Processes, (Yugoslavia), McGraw-Hill, NY, 1979, 304-06.

69. H. Kraushaar, R. Jeschar, V. Heidt, E.K. Jensen, and W. Schneider: in Light Metals 1995, J. Evans, ed., TMS, Warrendale, PA, 1995, pp. 1055-59.

70. J. Langlais, T. Bourgeois, Y. Caron, G. Beland, and D. Bernard: Light Metals 1995, J. Evans, ed., TMS, Warrendale, PA, 1995, pp. 979-86.

71. L. Maenner, B. Magnin, and Y. Caratini: Light Metals 1997, R. Huglen, ed., TMS, Warrendale, PA, 1997, pp. 701-07.

72. A. Larouche, J. Langlais, T. Bourgeois, and A. Gendron: in Light Metals 1999, M. Bouchard and A. Faucher, eds., TMS, Warrendale, PA, 1999, pp. 235-45.

73. I.J. Opstelten and J.M. Rabenberg: Light Metals 1999, C.E. Eckert, ed., TMS, Warrendale, PA, 1999, pp. 729-35.

74. J.Z. Jr., L. Katgerman, I.J. Opstelten, and J.M. Rabenberg: in Light Metals 2001, J.L. Anjier, ed., TMS, Warrendale, PA, 2001, pp. 873-78.

75. D. Li, M.A. Wells, and G. Lockhart: in Light Metals 2001, J.L. Anjier, ed., TMS, Warrendale, PA, 2001, pp. 865-71.

76. L.I. Kiss, T. Meenken, A. Charette, Y. Lefebvre, and R. Levesque: in Light Metals 2002, W. Schneider, ed., TMS, Warrendale, PA, 2002, pp. 981-85.

77. S.G. Hibbins: in Continuous Casting Vol. II: Heat Flow, Solidification and Crack Formation, J.K. Brimacombe, I.V. Samarasekera, and J.E. Lait, eds., ISS-AIME, Warrendale, PA, 1984, pp. 139-51.

78. J.B. Wiskel and S.L. Cockcroft: Metall. Mater. Trans. B, 1996, vol. 27B, pp. 119-27.

79. J.A. Bakken and T. Bergstrom: Light Metals 1986, TMS, Warrendale, PA, 1986, pp. 883-89. 
80. E.K. Jensen, S. Johansen, T. Bergstrom, and J.A. Bakken: Light Metals 1986, TMS, Warrendale, PA, 1986, pp. 891-96.

81. Y. Watanabe and N. Hayashi: in Light Metals 1996, W. Hale, ed., TMS, Warrendale, PA, 1996, pp. 979-84.

82. J. Sengupta, D. Maijer, M.A. Wells, S.L. Cockcroft, and A. Larouche: in Light Metals 2003, W. Schneider, ed., TMS, Warrendale, PA, 2003 pp. 841-47.

83. L. Bendig, M. Raudensky, and J. Horsky: in 78th Steel Making Conference Proceedings, Nashville, TN, 1995, ISS, 1995, 391-98.

84. M. El-Bealy, N. Leskinen, and H. Fredriksson: Ironmaking and Steelmaking, 1995, vol. 22 (3), pp. 246-55

85. L.K. Chiang: in 57th Electric Furnace Conference, 1999, Pittsburgh, PA, Iron \& Steel Society, Warrendale, PA, 1999, 653-70.

86. S.-M. Lee and S.-Y. Jang: Iron Steel Inst. Jpn. Int. (Japan), 1996, vol. 36 (Supplementary on Science and Technology of Steelmaking), pp. 208-10.

87. T. Kohno, T. Shima, T. Kuwabara, T. Yamamoto, M. Wake, and T. Tsuneoka: in Continuous Casting Vol. II: Heat Flow, Solidification and Crack Formation, I.V. Samarasekera, J.K. Brimacombe, and J.E. Lait, eds., ISS-AIME, Warrendale, PA, 1984, 133-37.

88. L.A. Baptista: Master's Thesis, University of British Columbia, Vancouver, 1979.

89. J.L. Dassel and T.C. Zinniger: Light Metals 1982, TMS, Warrendale, PA, 1982, pp. 793-801.

90. W. Schneider and E.K. Jensen: in Light Metals 1990, C.M. Bickert, ed., TMS, Warrendale, PA, 1990, pp. 931-36.

91. W. Schneider: in Light Metals 2002, W. Schneider, ed., TMS, Warrendale, PA, 2002, pp. 953-60.
92. H. Yu: Light Metals 1980, TMS, Warrendale, PA, 1980, pp. 613-28.

93. I. Wagstaff: U.S. Patent No. 4,693,298, 1987.

94. N.B. Bryson: "Casting of Aluminum Ingots," U.S. Patent No. 3,411,079, 1969.

95. A. Moitra: Ph.D. Thesis, University of Illinois, Urbana-Champaign, Urbana, IL, 1993.

96. F. Costes, A. Heinrich, and M. Bellet: in Modeling of Casting, Welding and Advanced Solidification Processes-X, TMS, Warrendale, PA, 2003, pp. 393-400.

97. A. Mo, M. Rappaz, and C.L. Martin: Aluminum, 2002, vol. 78 (10), pp. 856-64.

98. A. Henry: Light Met. Age, 2000, vol. 58 (7-8), pp. 66-67.

99. MSC-MARC Reference Manuals, MSC Software Corporation, Redwood City, CA, 2003.

100. ABAQUS Reference Manuals (Version 6.6), Hibbit, Karlson and Sorensen, Inc., Providence, RI, 2003.

101. A. Hakonsen and D. Mortensen: Modeling of Casting, Welding and Advanced Solidification Processes VII, TMS, Warrendale, PA, 1995, pp. 963-70.

102. H.G. Fjaer and E.K. Jensen: Light Metals 1995, TMS, Warrendale, PA, 1995, pp. 951-59.

103. H.G. Fjaer and A. Mo: Metall. Mater. Trans. B, 1990, vol. 21B, pp. 1049-61.

104. H.G. Fjaer and A. Hakonsen: Light Metals 1997, TMS, Warrendale, PA, 1997, pp. 683-90.

105. Aluminum: Project Fact Sheet, Newsletter published by Office of Industrial Technologies, Energy Efficiency, and Renewable Energy, United States Department of Energy (DOE), Washington, DC, 2000. 